IZA DP No. 8988

Permanent Wage Cost Subsidies for Older Workers: An Effective Tool for Increasing Working Time and Postponing Early Retirement?

Andrea Albanese

Bart Cockx

April 2015 


\title{
Permanent Wage Cost Subsidies for Older Workers: An Effective Tool for Increasing Working Time and Postponing Early Retirement?
}

\author{
Andrea Albanese \\ SHERPPA, Ghent University \\ and DEFAP Graduate School \\ Bart Cockx \\ SHERPPA, Ghent University, \\ IRES, IZA and CESifo
}

Discussion Paper No. 8988

April 2015

IZA
P.O. Box 7240
53072 Bonn
Germany
Phone: +49-228-3894-0
Fax: +49-228-3894-180
E-mail: iza@iza.org

Any opinions expressed here are those of the author(s) and not those of IZA. Research published in this series may include views on policy, but the institute itself takes no institutional policy positions. The IZA research network is committed to the IZA Guiding Principles of Research Integrity.

The Institute for the Study of Labor (IZA) in Bonn is a local and virtual international research center and a place of communication between science, politics and business. IZA is an independent nonprofit organization supported by Deutsche Post Foundation. The center is associated with the University of Bonn and offers a stimulating research environment through its international network, workshops and conferences, data service, project support, research visits and doctoral program. IZA engages in (i) original and internationally competitive research in all fields of labor economics, (ii) development of policy concepts, and (iii) dissemination of research results and concepts to the interested public.

IZA Discussion Papers often represent preliminary work and are circulated to encourage discussion. Citation of such a paper should account for its provisional character. A revised version may be available directly from the author. 


\section{ABSTRACT}

\section{Permanent Wage Cost Subsidies For Older Workers: An Effective Tool for Increasing Working Time and Postponing Early Retirement?}

In several OECD countries age-targeted wage subsidies have been introduced to increase the employment of older workers, but evidence on their effectiveness is scarce. This paper examines the effects of a permanent wage cost subsidy in Belgium on the employment rate, working time and hourly wage. We estimate these effects by integrating Inverse Probability Weighting in a, possibly trend-adjusted, Difference-in-Differences of endogenously sampled repeated cross sections. We find small positive short-run impacts on working time and larger ones on the employment rate, but only for employees at high risk of leaving to early retirement. The wage is not affected.

JEL Classification: J14, C21, J18, J3

Keywords: wage cost subsidies, older workers, weighted Difference-in-Differences, endogenous sampling

Corresponding author:

Bart Cockx

Ghent University

Sint-Pietersplein 6

B-9000 Gent

Belgium

E-mail: Bart.Cockx@ugent.be

\footnotetext{
${ }^{*}$ We are grateful for discussions with and comments of Muriel Dejemeppe, Michael Lechner, Simone Moriconi, Peter Mueser, William Parienté, Matteo Picchio, Yannick Thuy, Bruno Van der Linden, Vincent Vandenberghe, and the participants at the EALE conference in Lubjiana (09/2014) and at AIEL conference in Pisa (09/2014). We acknowledge financial support for this research project from the programme "Society and Future" of Belgian Science Policy (contract $n^{\circ}$ TA/00/044)" and from the special Research Fund of Ghent University for providing a scholarship to Andrea Albanese (code 01SF3612). We thank the Crossroads Bank for Social Security for the delivery of the data (report nr. 12/080 of the Sectoral Commission of Social Security and Health, department "Social Security").
} 


\section{Introduction}

The combination of the decreasing share of the working population induced by the ageing of the population and the longer life expectancy will be one of the major threats to economic growth and the Welfare State in the developed world in the coming decades. Partly in reaction to this threat, the European Union (EU) agreed in June 2010 on the "Europe 2020" strategy. One of the major targets is to raise the employment rate from $69 \%$ in 2010 to $75 \%$ by 2020 , and this, in particular, through a greater involvement of older workers in the work force (European Commission, 2010). Belgium has one of the lowest employment rates of older workers in the EU. In 2013 the employment rate among the population aged between 55 and 64 attained only $41.7 \%$ (50.3\% in EU27). Nevertheless, much progress has been made. Since 2000 the Belgian Federal government has implemented a series of policies to encourage the labour market participation of the elderly (Dejemeppe et al., 2015) and the employment rate among older workers has increased by 16.7 percentage points (Eurostat, 2015). The question is to what extent this positive trend has been driven by the policies put in place, and if so, which interventions have been the most effective. This paper contributes to a better understanding of this question by evaluating the impact on employment and wages of a wage cost subsidy targeted at older workers. Other countries have introduced similar wage subsidy schemes, widening thereby the scope of interest for our findings. ${ }^{1}$

In Belgium from the second quarter of 2002 onwards, the private sector employers' Social Security contributions (SSC) were automatically and permanently reduced by €400/quarter for employees older than 58 and working $80 \%$ of a full-time or more. For part-time employees working between $33 \%$ and $80 \%$ of a full-time, the subsidy was proportionally reduced, but employees working less than the lower threshold were not eligible. The average subsidy was worth $4 \%$ of the median wage cost, including all payroll taxes. This share increased with the wage, reaching a maximum intensity of $13.8 \%$ for someone working $80 \%$ of a full-time at the legal minimum wage. The policy is still in place and its coverage has even been extended in 2004 and $2007 .^{2}$ The cost of the programme is substantial: in 2004 expenditures on the payroll subsidy represented $0.034 \%$ of the GDP and between 2004 and 2011 in total about 1.3 billion euros of payroll reductions were spent.

To evaluate the policy we rely on an endogenously stratified random sample of 243,655 Belgians aged between 52 and 61 in 2002, the year that the subsidy was introduced. At these ages many individuals

\footnotetext{
${ }^{1}$ Examples in OECD countries are: Austria, Denmark, Finland, France, Germany, the U.S., the Netherlands, Sweden and the United Kingdom. A description of such measures introduced in the OECD countries is provided in Tables 1-3 of the Internet Appendix: http://users.ugent.be/ bcockx/IA Albanese Cockx.pdf.

2 In 2004 the age requirement was lowered to 57 and in 2007 the subsidy amount was increased, awarding a reduction already from age 50 (i.e. €50/quarter for each year above 49) if the worker has a quarterly remuneration lower than $€ 12,000$.
} 
(especially women) are not in the labour force in Belgium, and, if they are, their labour market mobility is low. Since we aim at evaluating the effect of the aforementioned subsidy on labour market transitions, and since privacy protection legislation forbids access to population data, we do not randomly draw a sample from the population, as the resulting data would contain many inactive individuals. Instead, we stratified the population and oversample individuals working in the salaried private sector or making labour market transitions during the period of analysis. However, because these strata are related to the outcomes of interest, they are endogenous, and consistent estimation of the treatment effect requires appropriate weighting of the data (Manski and Lerman, 1977; Cameron and Trivedi, 2005).

The data were sampled from merged administrative registers of the diverse Social Security institutions and of the National Register containing all Belgian inhabitants. These data are exceptionally rich in that they contain detailed information on labour market histories and the amount of SSC paid since 1998, and on private sector employment from as early as 1957. Using these data we assess the effects of the SSC reduction on the employment rate, working time and hourly wages. We base this assessment on a Conditional Difference-in-Differences (CDiD) estimator (Heckman et al., 1997). This estimator identifies these effects by contrasting the evolution in the outcomes between older and younger groups, conditional on a set of observed covariates including the labour market history of these individuals.

Our contribution to the literature is threefold. First, only few researchers have evaluated the impact of wage subsidies targeted at older workers. Ammermüller et al. (2006) and Brussig et al. (2006) have studied the impact of in-work benefits (subsidising the net wage of workers), Boockmann et al. (2012) of hiring subsidies (targeted to newly created jobs) and, more recently, Huttunen et al. (2013) of temporary wage cost subsidies for low-wage older workers. However, we are not aware of any study that evaluates the effects of a permanent wage cost subsidy targeted at all older workers, irrespectively of their wage, and precisely at the age that they become entitled to early retirement (58 in Belgium). The latter is of particular interest since it means that the subsidy targets a population that is at the margin of leaving the labour force and for which the potential of job retention is higher than at other ages. While most of the literature on the impact of early retirement schemes on the employment of older workers focused on supply side incentives (see e.g. Burtless, 1986; Krueger and Pischke, 1992; Gruber and Wise, 2007; Liebman et al., 2009; Staubli and Zweimüller, 2013), this paper provides evidence that also incentives at the demand side matter if there is a pay productivity gap for older workers. ${ }^{3}$ This gap may be induced by a declining productivity profile with age, as can be

\footnotetext{
${ }^{3}$ Hellerstein et al. (1999) are the first researchers to investigate this question. In this analysis they do not find evidence for a pay productivity gap in the U.S., but a recent replication of this seminal analysis reports that pay exceeds productivity for workers older than 55 in the manufacturing sector (Hellerstein and Neumark, 2007). Aubert and Crépon (2003, 2006)
} 
induced by rapid technological change, or by deferred compensation schemes (Lazear, 1979). This results in excess employment ("overmanning") at the going wage rate. In the absence of early retirement schemes, both anti-discriminatory legislation and the threat of labour dispute with trade unions refrain employers from dismissing these older workers, even if the costs of retaining them exceed the firing costs. Since employment already exceeds labour demand, a wage cost subsidy merely reduces this gap and does not affect the level of employment. This is in line with the existing empirical evidence of Boockmann et al. (2012) and Huttunen et al. (2013). For those at risk of entering early retirement the predictions are, however, different. Early retirement schemes can be seen as an agreement between employers and trade unions to make dismissals of older workers acceptable. ${ }^{4}$ Consequently, they reduce the level of excess employment. However, a wage cost subsidy reduces the attractiveness for employers to dismiss workers through early retirement, and, hence, positively affects employment through a higher retention rate.

Second, since the eligibility to early retirement at age 58 induces a significant drop in the employment rate, especially for males in the manufacturing sector, a panel DiD estimator in which the same individuals are followed over time is severely downward biased: it cannot distinguish between the effect of eligibility to the subsidy and the early retirement scheme, both starting at age 58. To eliminate this bias we fix the age and use a CDiD estimator based on a series of cross sections in both pre- and post-treatment periods. Following Lechner and Wunsch (2009), we explicitly control for the compositional biases that an analysis on different cross-sectional units induces. This estimator identifies the treatment effect of the subsidy under the assumption that in the absence of the policy the impact of the early retirement scheme is constant over time. A placebo test in the pre-treatment period does not reject this assumption for working time and hourly wage as outcome variables, but for the employment rate it is rejected. This rejection is caused by a differential time trend already present in the pre-treatment period between the treated and control groups. We therefore implement in this case a parametric trend adjusted version of this CDiD estimator (Wolfers, 2006).

Third, we integrate endogenous sampling weights in the CDiD estimator as to control for the aforementioned endogenous sampling. Frölich (2007) demonstrates in a standard Kernel matching framework that endogenous sampling, contrary to choice-based sampling (i.e. sampling based on the treatment status), requires an appropriate re-weighting of the data both in the estimation of the propensity score and the treatment effect. We apply this re-weighting within the Weighted Difference-in-Differences (WDiD) estimator of Abadie (2005), who implements CDiD by the Inverse

establish similar results for this age group in France, Ilmakunnas and Maliranta (2005) for Finland, and Cataldi et al. (2012) and Vandenberghe et al. (2013) for Belgium. By contrast, no pay-productivity gap is found in Portugal and in the Netherlands (Cardoso et al., 2011; van Ours and Stoeldraijer, 2011).

${ }^{4}$ This is considered as the main justification of the emergence of the early retirement scheme in Belgium (Claes, 2012, p. 38). 
Probability Weighting (IPW) estimator proposed by Horvitz and Thompson (1952) and Hirano et al. (2003), and advocated for by Busso et al. (2014). Within this approach it is simple to take the endogenous sampling into account, since it merely consists in a double re-weighting of the data, once to take the endogenous sampling into account and once to make the comparison groups comparable to the post-treatment treated group.

Our findings can be summarized as follows. In line with our theoretical expectations, the subsidy has a significant positive effect on the employment at the extensive margin only for workers at high risk of entering early retirement (i.e. in sectors where early retirement schemes are widely used). Decreasing labour costs for this group by $10 \%$ increases the employment probability by $9 \%$, implying an employment elasticity close to one. We cannot exclude, however, that this positive effect is partly driven by the substitution of older for younger workers. At the intensive margin, the subsidy scheme significantly increases working time. However, the elasticities of the wage cost subsidy at the intensive margin are small: 0.13 for men and 0.28 for women. Finally, the impact of the wage cost reduction on the hourly gross wage (excluding employer's SSC) is small and not statistically different from zero.

The paper is structured as follows. Section 2 summarizes the institutional setting. Section 3 reviews the theoretical and empirical literature on wage subsidies. Section 4 formulates theoretical predictions for the wage cost subsidy studied in this research. The sampling scheme and data are described in Section 5. Section 6 presents the identification strategy and the estimation method. In Section 7 we present our empirical findings and a cost benefit analysis. The last section concludes.

\section{The Institutional Setting in the Period around the Reform in 2002}

In Belgium wage negotiations between employer's organisations and trade unions take place in sectoral joint industrial committees ("commissions paritaires"), usually separately for blue and whitecollar workers. In case of dismissal and after a notice period, workers who have contributed sufficiently long to Unemployment Insurance (UI) are entitled to Unemployment Benefits (UB). The replacement rate at the start is $55 \%$ or $60 \%$ depending on the household situation, but there are caps and floors, so that it is higher (lower) for low (high) wage workers. UI in Belgium is singular in that there is no time limit to the entitlement, although the benefit level decreases with unemployment duration for individuals who are not head of household. Moreover, until June 2002 individuals aged 50 or more who were unemployed for more than one year were not required to be available for the labour market, and, in case they had accumulated more than 20 years of working experience, these long-term unemployed were entitled to a seniority supplement to their UB. Between 2002 and 2004 the age of labour market availability was gradually increased to 57 , but this availability was hardly 
verified at that time. Periods of unemployment are assimilated to periods of employment for the calculation of statutory pension rights. All in all, $\mathrm{UI}$ for workers above age 50 can in the facts be viewed as an early retirement scheme, but more generous schemes exist.

In Belgium there are essentially three early retirement schemes: early retirement within the statutory regime, the conventional pre-retirement scheme and the, so-called, "Canada Dry" system. ${ }^{5}$ Early retirement within the statutory regime starts from age 60 after minimum 30 years of employment experience. However, due to relatively low generosity of this scheme in the private sector, ${ }^{6}$ take-up in the two alternative regimes was much more important. For workers having more than 20 years of employment experience, the conventional pre-retirement regime (also known as the "bridge pension") is available from age 60 for all workers and from 58 in case of an agreement in the sectoral joint industrial committee, generally concluded in the manufacturing sector. In restructuring firms and for difficult physical professions, the age condition could drop to 50,52 or 55 , depending on the sectoral agreement. Because of a supplement equal to half of the difference between the UB and the wage and the favourable treatment for the statutory pension, the bridge pension is attractive for employees. The scheme imposes, however, a number of requirements on firms. They must pay the aforementioned supplement to UB and respect the legal notice period or, alternatively, pay severance allowances. Furthermore, supplementary SSC are due and there is an obligation to replace the employee by an unemployed worker during a period of three years, although exemptions to this obligation are awarded in 57\% of the cases (OECD, 2003, p. 75). Despite these requirements, employers' interest in the scheme lies in that it provides a solution to the pay-productivity gap for older workers induced by a declining productivity profile with age and, for white-collar employees, by deferred payment compensation schemes. Descriptive evidence of Vandenberghe et al. (2013, fig. 1) indeed suggests that in Belgium the average pay-productivity gap becomes positive from about age 56 onwards. ${ }^{7}$ Both anti-discriminatory legislation and the threat of labour dispute with trade unions refrain employers from dismissing these older workers, but by offering a generous early retirement employers can nevertheless do so while maintaining social peace with trade unions.

The "Canada Dry" is an unofficial early retirement scheme in which the employer pays, as in the conventional pre-retirement regime, a supplement to UB (half of the difference between the UB and the wage). This scheme is more flexible for the employer, since it does not impose an age limit, supplementary SSC, or replacement by a younger worker. Since there is no obligation for the worker

\footnotetext{
5 "Canada Dry" refers to publicity for the drink Canada Dry: "It has the colour of Whisky, but it is not Whisky".

${ }^{6}$ For public sector employees the scheme is much more generous and, hence, more widely used.

${ }^{7}$ This descriptive evidence is in line with the findings of their subsequent analysis that takes the endogenous composition of the older workforce into account, but does not provide exact information by age.
} 
to report the supplement to the UB she obtains, no official figures on the use of the Canada Dry scheme are available. The fact that the number of UB recipients older than 50 more than doubled between 1996 and 2001 (OECD, 2003, p. 80) while the number of individuals in the conventional preretirement scheme decreased, suggests that the scheme became more popular in that period.

In Belgium workers above the age of 50 who have more than 20 years of employment experience, among which 5 years full-time within the same firm, are encouraged to reduce working time either by $20 \%$ or by $50 \%$. This time credit scheme in the private sector ${ }^{8}$ is a right for the employee in firms employing 10 or more workers and in which no more than $5 \%$ of the workforce is already benefiting from the scheme. Since the employee is entitled to a monthly flat rate compensation until the age of statutory retirement, it is like a part-time retirement scheme (Ibid, p. 56).

Figure 1: The Quarterly Value of the Wage Cost Subsidy as a Function of Working Time

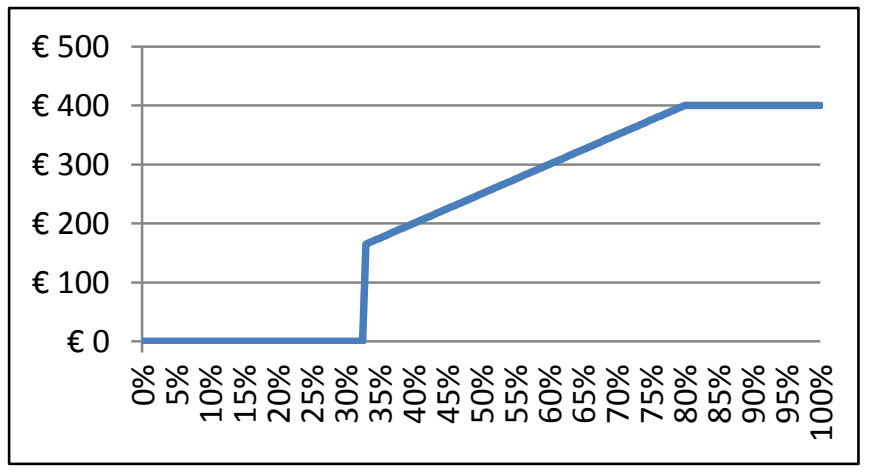

Fraction of a full-time

The permanent reduction of SSC for employers by $€ 400$ per quarter for private sector employees aged 58 or more, as well as the temporary hiring subsidy ("ACTIVA") awarded for maximum five years to employers recruiting workers unemployed for more than six months and aged 45 or more, both introduced in 2002, ${ }^{9}$ can be seen among the first attempts in Belgium to increase the employment rate of older workers rather than inducing withdrawal from the labour force. We focus our discussion on the first mentioned wage subsidy, because this is the object of analysis here. Figure 1 displays how the subsidy increases with working time. The subsidy favours part-time employment, since, between $33 \%$ and $80 \%$ of a full-time, it increases at a rate that is 1.25 times the share of working time relative to a full-time. Hence, it attains the maximum of $€ 400$ when working at least $80 \%$ of a full-time $(0.80 * 1.25 * 400=400)$. At $33 \%$ of a full-time the value of the subsidy is $€ 165(0.33 * 1.25 * 400=165)$. Below $33 \%$ the SSC reduction abruptly drops to zero. The average subsidy is worth $4 \%$ of the median

\footnotetext{
8 In the public sector a closely related "career break" scheme exists.

${ }^{9}$ The ACTIVA replaced an existing similar scheme, so that it was not really a new measure.
} 
wage cost, including all payroll taxes. This share decreases with the wage and is maximally equal to $14 \%$ for someone working $80 \%$ of a full-time at the minimum wage.

An essential feature of the subsidy is that it was awarded automatically to firms. This ensured a $100 \%$ take-up rate. This contrasts with other countries, such as the wage cost subsidy to low-wage older workers in Finland, for which employers had to apply and for which the take-up rate was much lower, i.e. about $60 \%$ (Huttunen et al., 2013). Similarly, in Belgium the take-up rate dropped to $89 \%$ for men and $70 \%$ for women when in 2004 the coverage of the subsidy was widened to those aged 57 or more, but no longer awarded automatically.

\section{Literature Review}

\subsection{Theory}

It is well known that in a competitive labour market wage subsidies may increase employment if both the supply and the demand for labour are sufficiently elastic, and that it does not matter whether these subsidies are paid to the employer or the employee: neutrality of the tax incidence (Marshall, 1920; Kaldor, 1936; Katz, 1996). In a partial equilibrium framework in which $E$ denotes employment, $W$ wage cost, $s$ the wage subsidy (at the employer- or employee-side), $\epsilon_{D}$ the absolute value of the uncompensated wage elasticity of labour demand and $\epsilon_{S}$ the uncompensated wage elasticity of labour supply, the standard textbook formulas are given by:

$$
\frac{d \ln E}{d \ln S}=\frac{1}{\frac{1}{\epsilon_{D}}+\frac{1}{\epsilon_{S}}} \text { and } \frac{d \ln W}{d \ln S}=\frac{1}{1+\frac{\epsilon_{S}}{\epsilon_{D}}}
$$

Pissarides (1998) demonstrates that also in non-competitive labour markets employment tax cuts may have substantial positive effects on employment to the extent that the income out of work is fixed in real terms and not indexed to the wage. Moreover he shows that targeting subsidies to low-wage workers may enhance the positive employment effects, since the tapering-off of the wage subsidy with the wage acts like a progressive tax making it more costly to capture part of the subsidy in a higher after tax wage. ${ }^{10}$

\subsection{Empirical Studies}

Based on more than 70 studies, Hamermesh (1996) suggests that the conditional elasticity of labour demand lies in the interval $[-0.15,-0.75]$, with -0.30 being the best available point estimate. More recently, Lichter et al. (2014) report, based on a meta-regression analysis, -0.246 as the preferred

\footnotetext{
${ }^{10}$ See also Hersoug (1984), Pissarides (1985), Lockwood and Manning (1993).
} 
point estimate, bracketed by the interval [-0.072;-0.446]. These elasticities exhibit substantial heterogeneity. For instance, the demand elasticity decreases with skill level and is higher for atypical employment. We are not aware of any study, however, that aims at specifically estimating the elasticity of labour demand for older workers.

Because older workers are wealthier than younger ones, one expects, through the negative income effect, the labour supply of older workers to be less elastic (e.g. Zabalza et al., 1980; Hanoch and Honig, 1983). Another strand of the literature reports, however, that labour supply is more elastic for older workers, both at the intensive (Friedberg, 2000; Keane, 2012) and the extensive margin (Mitchell and Fields, 1984; Blau and Riphahn, 1999; French, 2005; Keane and Rogerson, 2012). At the intensive margin the institutional setting, such as part-time retirement schemes, may enhance working time flexibility, while at the extensive margin the presence of early retirement schemes could make the decision to remain at work more sensitive to the wage. However, the labour supply elasticity at the extensive margin is asymmetric: elastic for withdrawal from the labour force, but inelastic for entry (Blau, 1994).

In view of the incomplete and partly mixed evidence on the demand for and the supply of older workers, it is difficult to predict the impact of wage cost subsidies for older workers. Another strand of the literature aims at directly estimating the impacts of wage subsidies. There exists a large literature on the effect of in-work benefits (employee-side wage subsidies), especially on the Earned Income Tax Credit in the U.S (e.g. Eissa and Liebman, 1996; Meyer and Rosenbaum, 2001; Eissa and Hoynes, 2004), that has found substantial positive employment effects, but we are only aware of two studies that evaluate the effect of subsidies targeted at older workers. Ammermüller et al. (2006) and Brussig et al. (2006) estimate the effect of an in-work benefit in Germany. Their DiD estimator shows a positive, but not significant, employment effect, which is higher in West Germany. The lack of significance is potentially due to the low take-up rate.

Overall reductions in employers' SSC are usually found to be absorbed by a higher hourly wage and, hence, effects on employment are insignificant (Bohm and Lind, 1993; Gruber, 1997; Bennmarker et al., 2009). However, in line with the theoretical predictions of Pissarides $(1985,1998)$, there is empirical evidence that payroll taxes targeted on low-wage workers do boost employment (Kramarz and Philippon, 2001; Crépon and Desplatz, 2003; Goos and Konings, 2007). Nevertheless, this positive finding disappears if the reduction of payroll taxes is targeted on low wage older workers. Huttunen et al. (2013) estimate by a triple DiD the impact of a temporary five-year reduction of payroll taxes in Finland for low-wage full-time employees aged over 54. Despite the precision of their estimates, they find small and statistically insignificant employment effects at both the extensive and the intensive 
margin, while no robust effects on wages. Only for the group aged over 58 some significantly positive effects on the intensive margin are reported. This could be related to the part-time retirement scheme to which workers of this age group were eligible at that age, since this may increase the elasticity of supply at the intensive margin. Finally, Boockmann et al. (2012) study the effects of hiring subsidy on older workers in Germany by DiD in duration analysis. Women in East Germany are the only group for whom significant employment effects are found. This might be due to the higher generosity of the subsidies and to the lower pressure on wages given the higher unemployment rate in this region.

\section{Theoretical Predictions}

From the overview of the literature we conclude that the few studies evaluating the effect of wage subsidies targeted to older workers find very small employment effects, if any. We argue that this could be a consequence of a pay-productivity gap for older workers. Declining productivity with age, possibly induced by rapid technological progress, especially in the manufacturing sector, and deferred compensation schemes make average pay exceeds average productivity of older workers. Vandenberghe et al. (2013, fig. 1) find that a positive pay-productivity gap emerges in Belgium on average from age 56 onwards, and at 58 (the age eligibility for the wage cost subsidy) wage costs exceed productivity by $12 \%$ on average. ${ }^{11}$ This has consequences for the effectiveness of a wage cost subsidy, but these consequences depend on whether targeted workers are at risk or not of leaving the labour force through early retirement. To support the basic intuition of our reasoning, we introduce a simple graphical exposition.

\subsection{The Effects of Wage Cost Subsidies for Older Workers in the Absence of Early Retirement}

In the absence of an early retirement scheme, employers refrain dismissing unproductive employees for the following reasons: (i) by the Employment Protection Legislation (EPL) they are required to pay severance payments; (ii) in case of deferred compensation, breaching the long-term contract harms their reputation and may prevent them to conclude new long-term incentive contracts; (iii) antidiscriminatory legislation makes it more costly to fire older workers; (iv) dismissing these workers increases the risk of a costly labour dispute with trade unions. As a consequence, employment exceeds labour demand among older workers and there is a pay-productivity gap. In Figure 2 this situation is represented by point $A$. To allow for wage bargaining and unemployment, point $A$ is not located on the labour supply $S_{0}\left(W^{c}\right)$. The pay-productivity gap is equal to the difference between the going wage $W_{0}^{c}$ and the marginal labour productivity $F^{\prime}\left(L_{0}\right)$ on labour demand $D_{0}\left(W^{c}\right)$. Suppose the government

\footnotetext{
${ }^{11}$ We thank Vincent Vandenberghe for providing the information to calculate these figures. These are descriptive figures, but the causal evidence reported in their paper is consistent with the descriptive evidence.
} 
introduces a wage cost subsidy $S$. This shifts the labour demand curve to the right, to $D_{2}\left(W^{c}\right)$ in Figure 2. However, the level of employment does not increase, since before the intervention employment was already exceeding the labour demand. This prediction is in accordance with the existing empirical evidence of Huttunen et al. (2013) for Finland. ${ }^{12}$ Depending on the bargaining power of trade unions, the net wage may increase, so that the pay-productivity gap decreases by less than the amount of the subsidy.

Figure 2: Effect of a Wage Cost Subsidy in the Presence of a Pay-Productivity Gap and Early Retirement

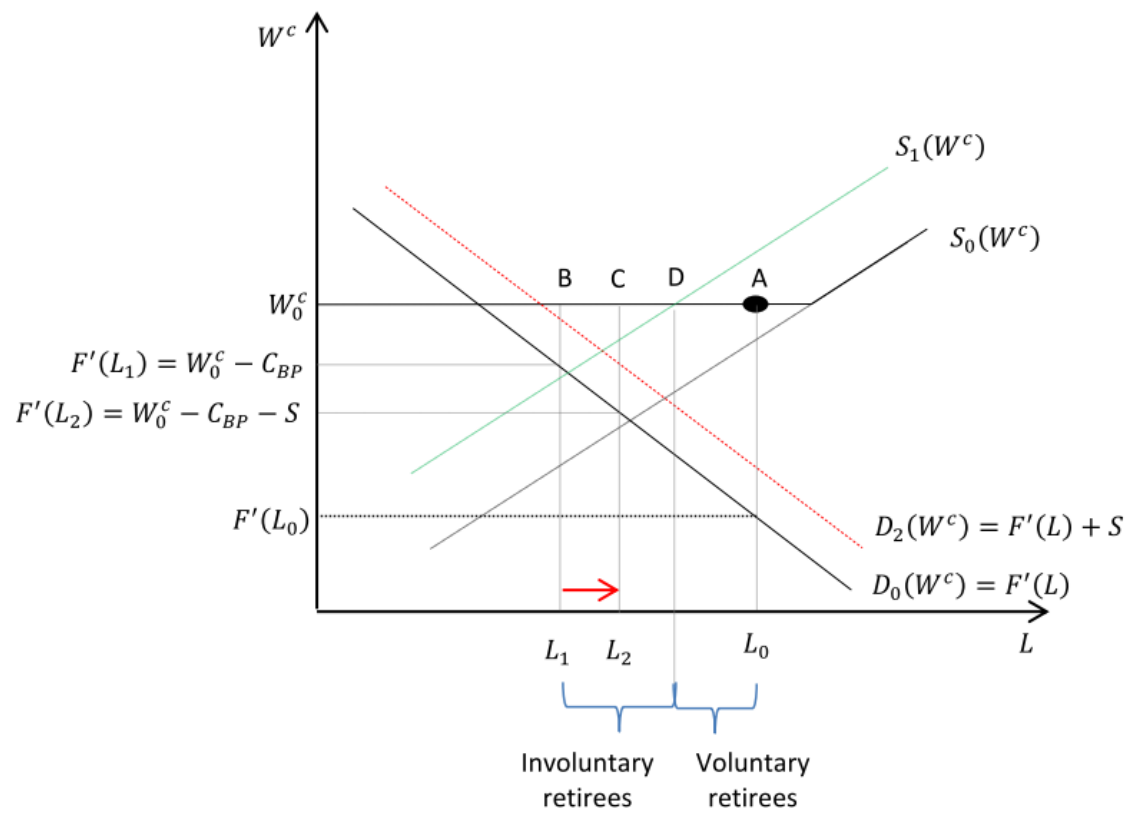

$W^{c}=$ wage cost $L=$ employment; $S\left(W^{c}\right)=$ labour supply; $D\left(W^{c}\right)=$ labour demand;

$F^{\prime}(L)=$ marginal labour productivity; $C_{B P}=$ employer's cost of bridge pension; $S=$ wage cost subsidy.

\subsection{The Effects of Wage Cost Subsidies for Older Workers in the Presence of Early Retirement}

In Belgium many workers in the manufacturing sector become eligible for early retirement at age 58, an age from which their employers are automatically awarded a reduction in SSC, i.e. a wage cost subsidy (see Section 2). First, consider the impact of the early retirement scheme. The early retirement scheme can be seen as an agreement between employers and trade unions, allowing employers to eliminate part of the pay-productivity gap while maintaining social peace (Claes, 2012, p. 38) and, hence, the impediments (ii)-(iv) to dismissal mentioned in Section 4.1. However, it remains costly for employers to recur to early retirement, because the employer must pay severance payments (cf. (i) in Section 4.1), the supplement to UB and higher SSC, and, in some cases they have the obligation to replace the employee by an unemployed worker (see in Section 2 the description of the bridge

\footnotetext{
${ }^{12}$ Notice that IImakunnas and Maliranta (2005) find evidence of a pay-productivity gap for older workers in Finland.
} 
pension). Suppose that these costs per retiree amount to $C_{B P}$. Consequently, employers will send some of their older employees to early retirement, up to a point that the marginal labour productivity is equal the wage cost minus the marginal cost of sending an employee to early retirement: $F^{\prime}\left(L_{1}\right)=W_{0}^{c}-C_{B P}$. Employment drops from $L_{0}$ to $L_{1}$ in Figure $2 .{ }^{13}$ This reduces, but not completely eliminates the pay-productivity gap. At the same time, as eligibility to early retirement increases nonlabour income out of work for the older workers, it shifts the labour supply curve to the left: from $S_{0}\left(W^{c}\right)$ to $S_{1}\left(W^{c}\right)$ in Figure 2 . This means that early retirement is partly voluntary, i.e. from $\mathrm{D}$ to $\mathrm{A}$, and partly involuntary, from $B$ to $D$. The share of involuntary to voluntary early retirement depends on the importance of the income effect on labour supply. Based on survey data, $40 \%$ of men and $30 \%$ of women report to be involuntary early retired in Belgium (Cohen and Elchardus, 2003).

Consider now a wage cost subsidy $S$ that shifts labour demand from $D_{0}\left(W^{c}\right)$ to $D_{2}\left(W^{c}\right)$. Because the employment choice before the introduction of the subsidy is optimal for the employer, in this case employment increases from $L_{1}$ to $L_{2}$ if the going net wage remains unaffected. Nevertheless, the more the early retirement scheme improves the outside option (and shifts labour supply to the left), the more likely that the wage subsidy will dissipate into a higher gross (net of employers' SSC) and part of the employment gain will vanish. This is unlikely to happen in the short-run, however. Consistent with this theoretical prediction, we find in our empirical analysis that the Belgian wage cost subsidy has a significant positive effect on employment for those workers who are at high risk of entering early retirement at age 58 and a small and statistically insignificant (short-run) impact on the hourly wage.

\subsection{The Effects of Wage Cost Subsidies for Older Workers on Employment at the Intensive Margin}

In general, the wage cost subsidy provides incentives to increase working time, since employers are not entitled to it if they employ individuals working less than $33 \%$ of a full-time and because the subsidy increases together with working time, up to $80 \%$ of a full-time (see Figure 1). Employers do not have incentives to increase the working time for all workers, but only for those for whom the marginal productivity of working exceeds the (post-subsidy) marginal cost. For this sub-population, the effect on working time is expected to be larger for workers with an elastic labour supply, such as for workers for whom in the absence of the subsidy the time credit scheme encourages to work part-time (see Section 2).

\footnotetext{
${ }^{13}$ This is the outcome of the following simple profit maximization problem in which we assume that employers always sends some employees to early retirement, i.e. $L_{0}>L$ (and here we set $S=0$ ): $\max _{L} F(L)-\left(W_{0}^{c}-S\right) L-\left(L_{0}-L\right) C_{B P}$. The first order condition for an interior maximum of this problem is: $F^{\prime}(L)=W_{0}^{c}-S-C_{B P}$.
} 


\subsection{Anticipatory and Substitution Effects of Wage Cost Subsidies for Older Workers}

Firms anticipate that the wage costs will also go down for younger employees, since they will become eligible to the wage cost subsidy as soon as they turn 58 . Hence, the subsidy may also positively affect the employment of younger workers (Huttunen et al., 2013, p. 55). However, to the extent that wages exceed costs also for these younger workers - which is confirmed in the aforementioned evidence of Vandenberghe et al. (2013) - and that these workers are less at risk of entering early retirement, we do not expect these anticipatory effects to be important.

By contrast, if older and younger workers are gross substitutes, the subsidy could also negatively affect the employment of the younger workers in the control group, since firms may substitute older for younger workers. We explained in Section 4.2 that we expect the subsidy to have employment effects because it postpones the early retirement of older workers. However, the subsidy also encourages firms to push younger instead of older workers into early retirement. The less stringent rules of the conventional pre-retirement scheme for restructuring firms and the Canada Dry system make this possible. The latter system exploits the feature of the Belgian UI that since 1996 long-term unemployed older than 50 are not required to be available for the labour market (Section 2). In the empirical analysis we therefore test whether any positive employment effect of the wage cost subsidy does not go at the expense of the employment of slightly younger workers.

Another type of substitution effect relates to the requirement that in about $43 \%$ of the industrial committees firms using early-retirement schemes are obliged to replace early retirees by unemployed workers (see Section 2). If in the counterfactual of no wage cost subsidy, the employer effectively hires an otherwise unemployed worker, then the jobs saved by the reduction in SSC contributions go at the expense of the hiring of these unemployed. However, we cannot assess the importance of this substitution with the available data as the replacement requirement is no guarantee that this hiring would not have taken place in the absence of the early retirement scheme.

\section{The Data}

The data were sampled from the "Data warehouse labour market and social protection" in which the Crossroads Bank for Social Security ${ }^{14}$ merges the administrative register data originating from the diverse Social Security institutions and the National Register of all Belgian inhabitants. The dataset contains individual information on gender, nationality, household and detailed labour market characteristics. Information on labour market histories is available since 1957 through the yearly

\footnotetext{
${ }^{14}$ See www.ksz-bcss.fgov.be/en/international/home/index.html.
} 
pension registrations, but these contain only information on salaried employment in the private sector and temporary salaried employment in the central administration of the public sector. From 1998 more detailed quarterly information is available covering all types of employment, including selfemployment, civil servants, and temporary salaried workers in the local public administration of provinces and municipalities. Table 1 lists the conditioning variables in these combined datasets that we use in the empirical analysis. ${ }^{15}$

Table 1: Conditioning Variables in the Data (at the moment that the outcome is measured, unless specified otherwise)

\begin{tabular}{|c|c|}
\hline $\begin{array}{c}\text { Province of residence } \\
\text { (at end of preceding year) }\end{array}$ & 11 Provinces \\
\hline Nationality & Belgian, European Union (EU), other \\
\hline \multirow{3}{*}{ Household Characteristics } & Single, single with children, couple, couple with children, other \\
\hline & Size of the household: $1,2,3,45+$ \\
\hline & Presence of members below 18 or above 65 years old (seven quarters earlier) \\
\hline \multirow{8}{*}{$\begin{array}{l}\text { Labour Market Characteristics } \\
\text { seven quarters earlier }\end{array}$} & Inactive, unemployed, public sector ${ }^{\ddagger}$, self-employed, civil servant \\
\hline & Elapsed unemployment duration in months \\
\hline & Actual working time in classes $0-30 \%, 31-80 \%, 80-100 \%$ \\
\hline & Sector dummies (Regrouped at 1 or 2 digit level) \\
\hline & Participation in Time Credit (Yes/No) \\
\hline & Unemployment benefit level ( $€^{*} /$ month) \\
\hline & Working time regime: Full-time, Part-time or special \\
\hline & Firm size: <5, 5-9, 10-19, 20-49, 50-99, 100-199, 200-499, 500-999, 1000+ \\
\hline \multirow{6}{*}{$\begin{array}{c}\text { Employment History as Salaried } \\
\text { Worker } \\
\text { (Excluding Civil Servants and } \\
\text { Employees in the Local Public } \\
\text { Sector) }{ }^{+}\end{array}$} & $\begin{array}{c}\text { Experience (in quarters) during: } \\
\text { Older history (between } 28 \text { and } 5.5 \text { years before); } \\
\text { Recent history (between } 11 \text { and } 7 \text { quarters before) }\end{array}$ \\
\hline & $\begin{array}{c}\text { Never employed during: } \\
\text { Older history (between } 28 \text { and } 5.5 \text { years before); } \\
\text { Recent history (between } 11 \text { and } 7 \text { quarters before) }\end{array}$ \\
\hline & $\begin{array}{c}\text { Number of times received a severance payment during: } \\
\text { Older history (between } 28 \text { and } 5.5 \text { years before); } \\
\text { Recent history (between } 11 \text { and } 7 \text { quarters before) }\end{array}$ \\
\hline & $\begin{array}{l}\text { Share of time worked as blue-collar during: } \\
\text { Older history (between } 28 \text { and } 5.5 \text { years before); } \\
\text { Recent history (between } 11 \text { and } 7 \text { quarters before) }\end{array}$ \\
\hline & $\begin{array}{c}\text { Average share of working during: } \\
\text { Older history (between } 10.75 \text { and } 5.5 \text { years before); } \\
\text { Recent history (between } 11 \text { and } 7 \text { quarters before) }\end{array}$ \\
\hline & $\begin{array}{l}\text { Average full-time quarterly gross earnings from salaried employment (in } €^{*} \text { ): } \\
\text { Recent history (between } 11 \text { and } 7 \text { quarters before) }\end{array}$ \\
\hline \multicolumn{2}{|c|}{$\begin{array}{l}\text { In constant } 2004 \text { euros, based on the Consumer Price Index. } \\
\text { The employment history excludes the career spent as self-employed, civil servant, and temporary employee in the local public sector } \\
\text { comprising the provincial and municipal authorities. Temporary employees in working in the central public administration are included. Since } \\
\text { the older history is based on a different source (the pension registrations) than the more recent history (the payroll-tax-administration), } \\
\text { was not possible to define a consistent labour market history between } 12 \text { to } 21 \text { quarters prior to the measurement of the outcome. Thi } \\
\text { labour market history is therefore missing. } \\
{ }^{\ddagger} \text { Public sector comprises both civil servants and temporary salaried workers in the public sector. }\end{array}$} \\
\hline
\end{tabular}

15 Because of the structural break in the data in 1998, and the identification strategy used it was not possible to define a consistent labour market history between 12 to 21 quarters prior to the measurement of the outcome. 
Privacy protection legislation forbids access to data on the full population but allowed the drawing of a sample of fixed size. Thus, we base the analysis on an endogenous sample of these register data containing 243,655 individuals born between the 1st of April 1941 and the 31st of March 1950, i.e. between 52 and 61 years old in 2002, the year that the subsidy was introduced. ${ }^{16}$ At these ages many individuals (especially women) are not in the labour force in Belgium, and, if they are, their labour market mobility is low. Since we aim at evaluating the effect of the aforementioned subsidy on labour market transitions, we stratified the data as to oversample individuals in the labour force and making labour market transitions during the period of analysis. This increases precision. However, these strata are related to the outcomes of interest, and, hence, endogenous. Therefore consistent estimation of population statistics and of the treatment effect requires appropriate weighting of the data (Manski and Lerman, 1977; Cameron and Trivedi, 2005).

Table 2: Retained Birth Cohorts and Corresponding Reference Periods

\begin{tabular}{|c|c|c|}
\hline & Cohort (quarter/year) & Reference Period (quarter/year) \\
\hline 1 & $2 / 41-1 / 42$ & {$[2 / 99-1 / 02]$} \\
\hline 2 & $2 / 42-1 / 43$ & {$[2 / 99-4 / 01]$} \\
\hline 3 & $2 / 43-1 / 44$ & {$[2 / 99-4 / 03]$} \\
\hline 4 & $2 / 44-1 / 45$ & {$[2 / 00-1 / 05]$} \\
\hline 5 & $2 / 45-1 / 46$ & {$[2 / 99-4 / 03]$} \\
\hline 6 & $2 / 46-1 / 47$ & {$[2 / 00-4 / 04]$} \\
\hline 7 & $2 / 47-1 / 48$ & {$[2 / 00-3 / 05]$} \\
\hline 8 & $2 / 48-1 / 49$ & {$[2 / 02-3 / 05]$} \\
\hline 9 & $2 / 49-1 / 50$ & {$[2 / 02-3 / 05]$} \\
\hline
\end{tabular}

To be more precise, we stratified the population for each gender in 9 birth cohorts defined in Table 2 . This stratification is exogenous to the outcomes of interest. Each of these 18 strata is subsequently endogenously stratified in five substrata, the definition of which depends on a different reference period for each birth cohort (see Table 2):

1. The population exiting salaried employment in the private sector within the reference period;

2. The population entering salaried employment in the private sector within the reference period and not contained in substratum 1 ;

3. The population employed throughout the reference period as salaried worker in the private sector and earning a gross wage lower than $€ 100$ per day at the start of this period;

4. The population employed throughout the reference period as salaried worker in the private sector and earning at least $€ 100$ per day at the start of this period;

5. The population that was not employed as salaried worker in the private sector during the reference period, i.e. individuals who were out-of-the- labour force, unemployed, selfemployed or working in the public sector.

\footnotetext{
${ }^{16}$ We drop individuals with missing information. This leaves us with 240,850 individuals ( $99 \%$ of the sample) for the analysis.
} 
Since labour mobility of older workers is low, we over-represented the transitions into and out of salaried employment in the private sector ${ }^{17}$ by sampling for each of the 18 strata the complete population of substratum 1 and 2. Low-wage workers as defined in substratum 3 are also oversampled relative to the high wage workers (substratum 4) and the population not employed in the private sector (substratum 5): in each of the 18 strata a random sample of 2,000 individuals is drawn in this substratum, while the sample size was 1,500 for substratum 4 and $5 .{ }^{18}$ Low-wage workers are oversampled, because the subsidy intensity decreases with the wage and wage cost subsidies are found to have larger effects for these workers (see Section 3).

The reference periods by birth cohort defined in Table 2 were chosen as to observe sufficient transitions in and out of private sector employment during the periods of analysis. However, as it was difficult to predict the exact identification strategy before having the data, these reference periods are not optimally chosen. ${ }^{19}$ Nevertheless, they are all situated around the period of interest, i.e. close to the introduction of the subsidy in the second quarter of 2002 and the sampling weights still allow us to make unbiased inference on the population.

As explained in more detail in the next section, the empirical analysis contrasts the evolution of a number of outcome variables (the employment rate, the fraction of individuals working less than $30 \%$ of a full-time worker, between $30 \%$ and $80 \%$, more than $80 \%$, the "approximate" fraction of a full-time that an individual works, ${ }^{20}$ and the hourly wage rate) between eligible workers (= treated group) and non-eligible younger workers (= control group). Table A.1 in the Appendix reports descriptive statistics of the conditioning variables listed in Table 1 for the treated and control groups used in the benchmark analysis. Since the empirical analysis is performed by gender, the male and female populations are explicitly distinguished in this descriptive analysis. Because of the endogenous stratified sampling, the individual observations $i$ belonging to birth cohort $c(=1,2, \ldots, 9)$ and to the substratum $s(=1,2, \ldots, 5)$ are reweighed by the sampling weights $S W_{i}$ as to obtain a correct description of the corresponding populations (Cameron and Trivedi, 2005):

$$
S W_{i}=\frac{N_{c s}}{N} * \frac{n}{n_{c s}}
$$

\footnotetext{
${ }^{17}$ We restrict the sample to private sector salaried employment, since only these workers are eligible to the subsidy.

${ }^{18}$ In cases that the population of the substratum was smaller than the population, the complete population was sampled.

${ }^{19}$ The data could only be obtained after a lengthy procedure, so that redefining the reference periods was not an option.

${ }^{20}$ We do not have information on hours, but on the fraction of working time in a quarter relative to a full-time worker in 10 percent classes. The "approximate" fraction is set to the midpoint of the corresponding time-class (e.g. 55.5 for someone who works between $51 \%$ and $60 \%$ of a full-time worker).
} 
where $N_{c s}$ denotes the size of the population in substratum $c s,{ }^{21} n_{c s}$ the corresponding sample size, $N \equiv \sum_{c=1}^{9} \sum_{s=1}^{5} N_{c s}$ the total population size and $n$ the corresponding sample size. As to avoid cumbersome notation, gender is not explicitly referred to. The weighting formula comes from a double re-weighting, within and between cohorts. ${ }^{22}$ Table A.1. also reports the p-values of the tstatistics testing the equality of the means between treated and control groups. Based on these statistics it is clear that treated and control groups are different in several dimensions. This justifies the use of a CDiD estimator.

\section{The Identification Strategy and Estimation Method}

Since the policy measure that we evaluate is targeted on a clearly defined sub-population (private sector employees aged 58 or more) and is introduced at a precise date (April 1, 2002), it is quite natural to use a simple DiD estimator to identify the Average Treatment Effect on the Treated (ATT) of the wage cost subsidy on a number of outcomes. Nevertheless, a number of factors complicate the analysis: (i) the early retirement scheme induces a significant drop in the employment rate at 58 , the same age at which the eligibility to the wage cost subsidy starts; (ii) anticipatory and substitution effects may affect the outcomes of control units; (iii) compositional differences between treated and control populations lead to a violation of the underlying identifying assumptions; (iv) the endogenously stratified sampling needs to be taken into account.

\subsection{Accounting for Age-Related Shocks in the Outcome Variable}

Figure 3 reports the evolution of the employment rate of birth cohorts turning 58 in the pre- (left panel) and in the post-treatment period (right panel). The employment rate declines with age, and this decline clearly accelerates at 58 and 60, ages at which people become eligible for early retirement (see Section 2). The drops in the employment rate are especially marked for men, because more men are employed in the declining manufacturing sector in which early retirement is more prevalent, while women tend to be more employed in the service sector. A consequence is that a panel DiD estimator in which the same individuals are followed over time is severely downward biased, even if we would take a trend adjusted version of it, since it cannot distinguish the effect of eligibility to the subsidy from that to the early retirement scheme, both starting at 58 . As shown by the lower blue lines in

\footnotetext{
${ }^{21}$ We have information on the population sizes in each substratum, i.e. on $N_{c s}$.

${ }^{22}$ First, to restore the representativeness within the cohorts we reweigh the units within each cohort by $S W_{c S}^{c}=\frac{N_{c s}}{N_{c}} * \frac{n_{c}}{n_{c s}}$ (where $N_{c}$ and $n_{c}$ is the size of the cohort in the population and in the sample). To make the cohorts in the sample representative for the population, we weight each cohort a second time: $S W_{c S}=S W_{c S}^{c} * \frac{N_{c}}{N} * \frac{n}{n_{c}}$, so that $S W_{c S}=\frac{N_{c S}}{N} * \frac{n}{n_{c S}}$.
} 
Figure 3 the drop of the employment rate at 58 is already present in the pre-treatment period..$^{23}$ This suggests that it is possible to account for this drop by implementing a DiD estimator based on repeated cross-sections in which the age of treated and control groups is fixed over time instead of the individual. In the baseline model we compare treated units aged 58 to 59.5 to control units aged 53.25-55.25. The choice of the age range of the control group is related to the issue of anticipatory and substitution effects. The maximum age of the treated units is 59.5 as in our data this is the oldest cohort at the beginning of the pre-treatment period.

Figure 3: Employment Rate of Birth Cohorts Turning 58 in the Pre- and Post-Treatment Period

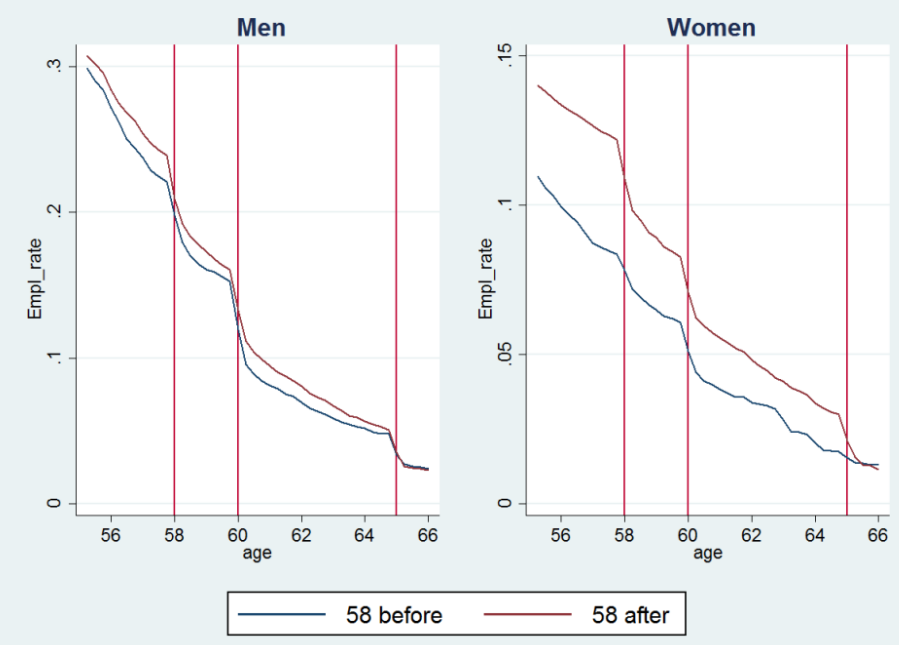

Evolution of the employment rate of birth cohorts turning 58 during the pretreatment period (left panel) and in the post-treatment period (right panel). The vertical red lines indicate the quarter in which the cohort turns 58, 60 and 65 . Employment rates are weighted by the sampling weights defined in Equation (2).

\subsection{Anticipatory and Substitution Effects}

In Section 4.4 we argued that the wage cost subsidy may induce anticipatory or substitution effects on workers younger than 58. If the younger control group is affected by anticipatory effects this would bias the ATT downwards, while substitution effects would lead to an upwards bias. We argued that substitution effects are likely to be a more important concern than anticipatory effects.

Independently of which of these two effects is dominant, we must avoid selecting the control groups who are just slightly younger than 58 , because the aforementioned spill-over effects are likely to be more important the closer the age eligibility threshold. The youngest age at which we can select control individuals within the available sample and given the chosen methodology is 53.25 years. In

\footnotetext{
${ }^{23}$ The drop of the employment rate in the post-treatment period is even larger, suggesting a negative effect of the wage cost subsidy on employment. However, this is descriptive evidence, which does not condition on the predetermined variables and does not control for the differential trend in the employment rates of treatment and control groups (see below).
} 
the baseline analysis we will therefore define control groups as individuals in the age range 53.2555.25. In a sensitivity analysis we then increase the upper range of these control groups to 57 years. By comparing the magnitude of the effects obtained in the baseline and in the sensitivity analysis, we can judge to what extent these spill-over effects are important and which of the two dominates.

Another type of anticipatory effect needs to be taken into account. Because the policy plan was discussed in the media, it could have been anticipated by employers before it was enacted. The fact that the wage cost subsidy has been implemented retroactively - the Royal Decree for this measure was published only on the $26^{\text {th }}$ of June 2002 , while the subsidy was already granted from April 1 makes such anticipation less likely. Nevertheless, in the analysis we end the pre-treatment period on the $31^{\text {st }}$ of December 2001 and, hence, allow for such anticipation during the first quarter of 2002.

Figure 4: DiD with Multiple Repeated Cross Sections: Fixing Age over Time

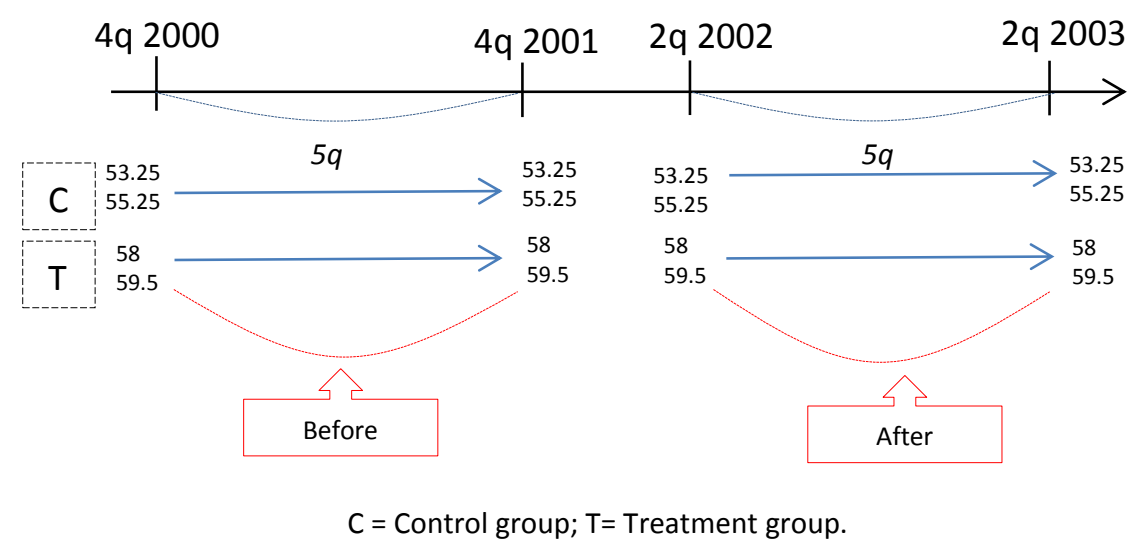

Figure 4 graphically represents the DiD methodology used in the baseline analysis. The post-treatment period starts in the second quarter of 2002, when the subsidy was awarded for the first time. We limit the analysis to the short run as the treatment period ends five quarters later, in the second quarter of 2003. This end is determined by the reform in January 2004 that reduced the age eligibility threshold to 57 and excluded several sectors from the reduction (e.g. health services, education and hotels). We stop the evaluation period two quarters earlier to allow for anticipatory effects of this reform. The outcomes are measured at the end of each quarter in the pre- and post-treatment periods for both control and treatment groups. We fix in each quarter the age range of the treated groups from 58 to 59.5 years and for the control groups from 53.25 to 55.25 years. Formally the DiD estimator amounts to estimating the following linear regression equation, which is a slight modification of the standard version (Meyer, 1995), since it involves multiple pre- and post-treatment periods:

$$
Y_{i q}=\alpha+\sum_{q=-4}^{5} \alpha_{q} * T_{q}+\beta * D_{i q}+\sum_{q=0}^{5} \delta_{q} * D_{i q} * T_{q}+\epsilon_{i q}
$$

where 
- $q=-5,-4, \ldots,-1$ denotes the five quarters in the pre-treatment period, $q=1,2, \ldots, 5$ denotes the five quarters in the post-treatment period, and $q=0$ denotes the first quarter of 2002 , during which firms may anticipate the introduction of the wage cost subsidy;

- $Y_{i q}$ is the outcome measured for individual $i$ in quarter $q$;

- $D_{i q}=1$ if individual $i$ is between 58 and 59.5 years old in quarter $q$ and, hence, belongs to the treated group;

- $D_{i q}=0$ if individual $i$ is between 53.25 and 55.25 years old in quarter $q$ and, hence, belongs to the control group; ${ }^{24}$

- $T_{q}=1$ if the time period in which the outcome is measured is quarter $q$ and $T_{q}=0$ otherwise.

The time effects are captured by the constant term $\alpha$ measuring the effect in quarter $q=-5$, and by $\alpha_{q}$ (for $q=-4,-3, \ldots, 5$ ) measuring the time effects in deviation from the first quarter. The effect of belonging to the treatment group - aged between 58 and 59.5 - is captured by $\beta$. The ATT in quarter $q$ $(q=0,1, \ldots, 5)$ is measured by $\delta_{q}$. The error term of the regression is $\epsilon_{i q}$.

\subsection{Accounting for Compositional Differences Between Treated and Control Groups}

At the end of Section 5 we mentioned that the observed composition of treatment and control groups differs on average. This does not invalidate a DiD analysis to the extent that these differences remain constant over time, but this is not the case as in each quarter new individuals enter and exit the two groups. We therefore apply a CDiD estimator (Heckman et al., 1997) in which we explicitly control for possible compositional biases in this multi-period framework. This estimator requires that, conditional on the observed explanatory variables, the outcomes of treated and control groups evolve according to a parallel trend in the absence of a treatment. Moreover, by conditioning on observed covariates treated and control units become more comparable, which makes the DiD less vulnerable to the assumption that the selection on unobservables should be additive (Athey and Imbens, 2006).

\section{Choice of the Conditioning Variables and the Identification strategy}

We listed in Table 1 the conditioning variables that we use in the empirical analysis. Among these variables are lagged outcomes of interest and other potentially endogenous variables. Since the posttreatment period, including the first quarter of 2002 during which the policy might have been anticipated, lasts six quarters, we ensure that these lagged variables are predetermined by measuring them all at least seven quarters prior to the outcome variable of interest.

\footnotetext{
${ }^{24}$ Individuals belonging neither to the treated nor the control group in a given q are not used in that quarter.
} 
In their survey article, Imbens and Wooldridge $(2009$, p. 70 ) have expressed doubts on whether the CDiD estimator can improve upon the standard matching estimator in case panel data are available, so that lagged outcomes can be conditioned upon. The intuition is that if one conditions on the same pretreatment outcome in the pre- and post-treatment period, then it is difficult to see how differencing can make treated and control units more comparable, since the pre-treatment outcome already captures the selection on the individual fixed effect. However, as argued by Chabé-Ferret (2012), this intuition no longer holds if one allows for selection on transitory shocks in the outcome variable.

Our setting is different from the aforementioned literature. We do not have a standard panel data setting since, as mentioned in Section 6.1, the treatment is selected on an age related shock induced by the availability of the early retirement scheme (the "bridge pension") at age 58 . We therefore implement the CDiD estimator based on repeated cross sections (containing panel information) in which we fix the age (instead of the individual) in both treated and control group. In such a setting the pre-treatment outcomes differ between pre- and post-treatment period, because they refer to different individuals. Even if the standard matching estimator makes these individuals similar in terms of employment history and other characteristics, it cannot eliminate fixed unobserved age-related differences between the older treatment group and the younger control group. Figure A.1 indeed shows that in the pre-treatment period large differences in outcomes between treated and control group remain even if these groups are appropriately matched. ${ }^{25}$ However, since, apart from the employment rate, these differences are constant over time, i.e. display a "parallel trend", ${ }^{26}$ the CDID differences this unobserved age effect out. By contrast, for the employment rate we observe a differential trend, which suggests an alternative identification strategy to which we return below.

\section{The Implementation Method}

In order to estimate the ATT, Heckman et al. (1997) implement the CDiD method by matching control to treated units on the basis of the propensity score (PS) before taking the double difference in the outcomes. In this paper we instead apply the Weighted DiD (WDiD) estimator of Abadie (2005). This estimator makes the control units comparable to the treated by Inverse Probability Weighting (IPW) as proposed by Horvitz and Thompson (1952) and Hirano et al. (2003). Busso et al. (2014) advocate using this method in cases that overlap of the distribution of the PS between treated and control groups is good, ${ }^{27}$ which is the case in this empirical application. Based on the efficient trimming rule of Crump et

\footnotetext{
${ }^{25}$ As explained below, we do not match to make treated and control units comparable, but instead weigh the observations.

${ }^{26}$ This hypothesis cannot be formally rejected based on the placebo tests defined below.

${ }^{27}$ In an empirical Monte Carlo analysis Huber et al. (2013) confirm the reliability of IPW, although it is outperformed by some alternative matching estimators. More recently, Frölich et al. (2015) have found that the IPW in which the PS is parametrically estimated is one of the best performing estimators after a few non-parametric estimators.
} 
al. (2009), which removes the units with a PS above a certain threshold, we trimmed over all estimations at most $0.4 \%$ of the reference treatment group defined below. ${ }^{28}$ Other reasons for choosing this estimator is that it is simple to take the endogenous sampling present in our data into account and that it is not very computationally intensive, which matters given the large sample size, the CDiD framework with multiple periods and that we bootstrap the standard errors (see below).

The WDiD estimator can be implemented by estimating regression Equation (3) by Weighted Least Squares (WLS). Since we implement the WDiD estimator with a series of cross-sections instead of the usual four treated/control groups and before/after periods, we must modify the standard procedure (Blundell et al., 2004) and choose a reference treatment group to which we make the other groups comparable (Lechner and Wunsch, 2009). We choose the treated group in the second quarter of 2002, i.e. $q=1$, to be this reference.

The estimation procedure then consists of the following steps:

1. Estimate, using the observed conditioning variables $X_{i q}$ for individual $i$ in quarter $q$, the PS of belonging to the reference treatment group $\left(T_{1}\right)$ for all treated $\left(T_{q}\right)$ and control groups $\left(C_{q}\right)$ in all quarters $q \neq 1$, and for just the control group $C_{1}$ if $q=1$, by logistic regressions. $^{29}$

2. Trim the data on the basis of Crump et al.'s (2009) efficient trimming rule. ${ }^{30}$ The trimmed treated group in $q=1$ is composed of the intersection of all the common supports in all the estimations of the PS

3. Re-estimate the PS on the trimmed data and denote the corresponding estimates of the PS by $\hat{P}^{J}\left(X_{i q}\right)$, where $J \in \Gamma \equiv\left\{T_{-5}, C_{-5}, T_{-4}, C_{-4}, \ldots, C_{0}, C_{1}, T_{2}, \ldots, T_{5}, C_{5}\right\}$.

4. Estimate Equation (3) by WLS using the following weights:

$$
P W_{i}=\frac{\hat{P}^{J}\left(X_{i q}\right)}{1-\hat{P}^{J}\left(X_{i q}\right)} / \frac{1}{N^{J}} \sum_{i=1}^{N^{J}} \frac{\hat{P}^{J}\left(X_{i q}\right)}{1-\hat{P}^{J}\left(X_{i q}\right)} \quad \text { for } \mathbf{i} \in \mathrm{J} \text { and } \mathrm{J} \in \Gamma \text {, and } \mathrm{PW} \mathrm{i}=1 \text { for } \mathrm{I} \in \mathrm{T}_{1}
$$

where $N^{J}$ denotes the number of individuals in group $J$ and where, following Busso et al. (2014), we normalize the weights to one by dividing the individual weight by the average weight in the corresponding group. ${ }^{31}$

\footnotetext{
${ }^{28}$ We also tried out the alternative trimming rule proposed by Huber et al. (2013), but according to this rule virtually no individuals should be discarded from the treatment group, even if we decrease the threshold of the trimming weight from $4 \%$ to $1 \%$. This may be related to the much larger sample size in this application relative to the largest one used in the aforementioned paper. On the other hand, it is also a confirmation that the overlap is good in our empirical application.

${ }^{29}$ Since the membership to the treated or control group depends on the age of the individual, it depends on the quarter in which the individual is observed. This justifies the presence of subscript $q$ in $C_{q}$ and $T_{q}$.

${ }^{30}$ The trimming eliminates treated units outside of the common support.
} 


\section{Endogenous Sampling}

In Section 5 we explained that our sample is endogenously stratified. Frölich (2007) demonstrates in a standard Kernel matching framework that, contrary to choice-based sampling, endogenous sampling requires appropriate re-weighting of the data both in the estimation of the propensity score and the treatment effect. It is straightforward to implement these adjustments for our WDiD. First, in steps 1 and 3 we weight each observation in the logistic regressions by the sampling weights $S W_{i}$ defined in Equation (2). Second, in step 4 a double weighting should be applied by replacing $P W_{i}$ by $P W_{i}{ }^{*} S W_{i}$.

\section{Statistical Inference}

By weighting, the Least Squares estimator becomes heteroskedastic. In addition, the fact that individuals may belong to multiple cross-sections considered in our WDiD estimator induces serial correlation. Correct inference requires therefore using cluster-robust standard errors. However, these cluster-robust standard errors lead to conservative inference, since they do not take into account that the PS in the weights $P W_{i}$ are estimated. It has indeed been shown in the literature that taking into account that the PS are not known, but estimated in a first step can increase the precision of the estimator (Hirano et al., 2003; Wooldridge, 2010, pp. 500-502 and 824-827). We do this by bootstrapping the standard errors. Since our data come from an endogenously stratified sample, we cannot apply a standard bootstrap, however. Instead we implement a stratified bootstrap by randomly drawing for each replication $n_{c s}$ individuals within each cohort-stratum $c s$. This is valid because in the sampling individuals within each cohort-stratum are randomly drawn. Notice, as to account for serial correlation, we re-sample within each replication the same individuals in all cross-sections. Because of the large sample size and the high number of times we have to estimate the PS to obtain the ATT (i.e. 42 for each outcome and population considered), we limit the number of replications in the bootstrap to 200. The reported standard errors are the empirical estimates in the bootstrap sample. Confidence intervals are constructed on the assumption of Normality.

\section{Placebo Tests and Parametric Trend-Adjusted WDiD}

The WDiD crucially depends on the assumption that the double weighted outcomes of treated and controls follow a parallel path in the absence of the treatment. We have already mentioned that graphically the outcome variables, apart from the employment rate, clearly display a parallel trend (see Figure A.1 in the Appendix). We also test for this formally in the following placebo test. We divide the pre-treatment period in two (grouping the first three and the last two quarters of this period) and

\footnotetext{
${ }^{31}$ Stata automatically normalizes the weights in the regression by specifying the option pweights. Since the normalization performed by Stata is slightly different (it divides the individual weight by the average weights of the whole sample), we recommend manually normalizing the weights (i.e. by treatment status).
} 
implement the WDiD estimator (maintaining $T_{1}$ as reference group) on this subsample by assimilating the last quarters of the pre-treatment period to a placebo post-treatment period. The placebo test consists in testing whether the placebo treatment has a statistically significant effect.

If the placebo test is rejected, which is the case for the employment rate, we propose a parametric trend adjusted WDiD estimator similar to the one proposed by Wolfers (2006), rather than the nonparametric one proposed by Bell et al. (1999) and Blundell and Costa Dias (2009), because the pretreatment period is too short (five quarters) to implement the non-parametric version. We do this because the graphical analysis of the evolution in the employment rate in the pre-treatment period clearly displays a differential time trend between treated and control groups (see Figure A.1 - top panel - in the Appendix). ${ }^{32}$ If the difference in growth rate in the employment of the two groups remains constant, i.e. we can rely on parallel growths rather than parallel paths, then the trend adjusted WDiD is a consistent estimator. Such parallel growths imply that the employment rate of younger generations (the control group) declines at a lower rate than that of the older ones (the treatment group). A possible explanation for the differential evolution in the employment rate is the data do not contain information on the level of educational attainment. Since we cannot condition on this level in the empirical analysis, the slower decline in the employment rate for the younger generations may be caused by higher level of educational attainment of the younger relative to the older generations, since the high educated withdraw less rapidly from the labour market than the low educated. The parametric trend adjusted estimator consists in adding a common $\gamma * q$ and a differential trend for the treatment groups $\mu *\left(q * D_{i q}\right)$ in regression Equation (3) and to subsequently follow the same estimation steps as described earlier:

$$
Y_{i q}=\alpha+\sum_{q=-3}^{5} \alpha_{q} * T_{q}+\beta * D_{i q}+\gamma * q+\mu *\left(q * D_{i q}\right)+\sum_{q=0}^{5} \delta_{q} *\left(D_{i q} * T_{q}\right)+\epsilon_{i q}
$$

Note that identification of these trends requires normalizing one common quarterly time effect to zero. We choose to set $\alpha_{-4}=0$.

\section{Results}

In this section we report the results of our estimations. The analysis is performed separately for men and women. We focus on the following outcomes: the employment rate (i.e. the extensive margin), the time worked (i.e. the intensive margin) in three categories (less than $30 \%$ of a full-time worker, between $30 \%$ and $80 \%$, and more than $80 \%$ ), a measure approximating working time and the hourly

\footnotetext{
32 As the parallel path for the intensive margin of women and the gross hourly wage is not consistent between the $4^{\text {th }}$ quarter 2000 and the $1^{\text {st }}$ quarter 2001, for these scenarios we start the pre-treatment period in the $1^{\text {st }}$ quarter of 2001.
} 
wage rate. For the employment rate as outcome variable, we do not only report the ATT on the total population within the selected age category (58-59.5), but also on the sub-population that is already in salaried employment in the private sector seven quarters before the measurement of the outcome. We focus on the effect of the latter group, since, if the wage cost subsidy has any effect on the employment of older workers, it is more likely to have an effect on the separation rate than on the hiring rate (see Section 3). For each of the outcomes we also estimate the ATT on particular subpopulations (for the employment rate within the subpopulation that is already employed): lowwage workers earning less than the median wage in the aforementioned employed subpopulation, blue and white-collar workers, manufacturing sector and service sector, large firms and small firms, and salaried workers employed in sectoral joint industrial committees ("commissions paritaires"; see Section 2) in which in the pre-treatment period the exit rate from employment was for employees aged 57.75 within the next two quarters above or below the median rate (i.e. 18\%). ${ }^{33}$ The latter two subpopulations were constructed with the aim of testing our hypothesis that the employment effect of the wage cost subsidy is significantly positive only for employees with a high risk of entering early retirement at 58 (see Section 4.2). The inclusion of separate effects for blue-collar workers and employees in the manufacturing sector has the same justification, since these subpopulations were at higher risk of entering early retirement. Except for the employment rate, we estimated the effect of the wage cost subsidy by WDiD. Since for the employment rate the placebo test failed, we estimated the ATT for this outcome by the trend adjusted WDiD. The PS-reweighted sample was always well balanced. In $98 \%$ of the 1,680 times that we reweighted the units, not any variable had a Standardized Bias above $5 \%$. Moreover, the lowest p-value of the log-likelihood test was 0.98 and the highest Rsquared $0.002 .{ }^{34}$ Here we limit to reporting the average ATT of the subsidy in the post-treatment period, i.e. $\bar{\delta} \equiv \sum_{\mathrm{q}=1}^{5} \delta_{q} / 5^{35}$

\subsection{Effect on the Employment Rate}

Table 3 reports both for men (top panel) and women (bottom panel) the ATT of the wage cost subsidy on the employment rate of the population aged between 58 and 59.5 (first column), as well on those already employed 7 quarters earlier (all columns beyond the first). The overall ATT is positive but insignificantly different from zero: the reform enhanced the employment rate of men by 0.4 percentage points $(p p)$ and of women by $0.3 p p$ on average. In terms of semi-elasticities, this effect is

\footnotetext{
33 In case the information of the industrial committee was missing, the separation rate of the sector was considered.

${ }^{34}$ The two last mentioned tests were proposed by Sianesi (2004).

35 More detailed estimation results for the overall population and for the high and low exit rate committees can be found in an Internet Appendix: http://users.ugent.be/ bcockx/IA Albanese Cockx.pdf. Other results are available from the authors upon request.
} 
comparable to the ones that were found by Huttunen et al. (2013). A $10 \%$ increment of the subsidy increases the employment rate for men by $1.1 p p$ and for women by $0.5 p p$, which is very close to the range of 0.44 to $0.86 p p$ reported by Huttunen et al. for the temporary wage cost subsidy in Finland (Ibid., p. 57). However, since the employment rate of the older workers in Belgium is much lower, the implied employment elasticities are much higher in Belgium than in Finland: 0.6 and 0.7, respectively for Belgian men and women, while in Finland the corresponding elasticity is about 0.1 .

In Section 4.1 we argued that in the absence of early retirement schemes we do not expect a wage cost subsidy to have any impact on employment, since the pay-productivity gap for older workers results in employment in excess of labour demand and the wage cost subsidy is insufficiently large to reverse this gap. Firms actually would prefer firing their older employees, but are inhibited doing so, because of employment protection regulation and because trade unions threaten them with social disruptions. The finding of an insignificant overall impact of the wage cost subsidy on employment is in accordance with this hypothesis.

Nevertheless, in Section 4.2 we also argued that the economic environment is different for those salaried employees whose working conditions are determined by joint industrial committees that have agreed on allowing dismissals to early retirement at age 58 , the same age threshold at which workers become eligible for the reduction in employers' SSC. For these workers the subsidy may prevent entry in early retirement and, hence, have a positive effect on the employment rate. Since these agreements were usually concluded for blue-collar workers in the manufacturing sector, we would expect the effect of the subsidy to be concentrated on these groups. For men working in the manufacturing sector the subsidy did indeed significantly increase employment by $2.4 \mathrm{pp}$. For women the impact is also $2.4 p p$, but statistically insignificant, presumably because most women work in the service sector. However, for blue-collar workers, no significant effects are found, but this might be because we did not restrict to blue-collar workers for whom an agreement facilitating access to early retirement was concluded. This is why we tried to refine our measurement by constructing the aforementioned indicator identifying workers at high risk of entering early retirement at age 58. For these groups of workers the impact is large (2.2 pp for men and $3.1 p p$ for women) and statistically significant for men, but not for women (a p-value of 0.132). The lower precision of the effect for women is most likely caused by the much lower female employment rate in that age class: it is less than half as large as the male one. This corresponds to an employment elasticity of the subsidy of 0.9 for both men and women. 
Table 3: Impact on the Employment Rate (Extensive Margin)

\begin{tabular}{|c|c|c|c|c|c|c|c|c|c|c|c|}
\hline Men & $\begin{array}{c}\text { Overall } \\
\text { (1) }\end{array}$ & $\begin{array}{c}\text { Already } \\
\text { Working (2) }\end{array}$ & $\begin{array}{c}\text { Low Wage } \\
\text { (3) }\end{array}$ & $\begin{array}{c}\text { Manufacturing } \\
\text { Sector (4) }\end{array}$ & $\begin{array}{c}\text { Service } \\
\text { Sector (5) }\end{array}$ & $\begin{array}{l}\text { High Exit Rate } \\
\text { Committee (6) }\end{array}$ & $\begin{array}{l}\text { Low Exit Rate } \\
\text { Committee (7) }\end{array}$ & $\begin{array}{c}\text { Large Firms } \\
(8)\end{array}$ & $\begin{array}{c}\text { Small Firms } \\
\text { (9) }\end{array}$ & $\begin{array}{c}\text { Blue-collar } \\
\text { (10) }\end{array}$ & $\begin{array}{c}\text { White-collar } \\
\text { (11) }\end{array}$ \\
\hline ATT in $p p$ & 0.4 & 1.5 & 0.9 & $2.4^{*}$ & 0.6 & $2.2^{* *}$ & -0.3 & 2.4 & -1.0 & 0.3 & 1.7 \\
\hline $95 \% \mathrm{Cl}$ & {$[-0.3 ; 1.1]$} & {$[-0.4 ; 3.4]$} & {$[-1.3 ; 3.1]$} & {$[-0.2 ; 4.9]$} & {$[-2.1 ; 3.3]$} & {$[0.0 ; 4.5]$} & {$[-3.1 ; 2.5]$} & {$[-1.2 ; 6.1]$} & {$[-3.3 ; 1.3]$} & {$[-1.9 ; 2.6]$} & {$[-0.6 ; 4.0]$} \\
\hline $\begin{array}{l}\text { Pvalue } \\
\end{array}$ & 0.243 & 0.113 & 0.436 & 0.066 & 0.655 & 0.048 & 0.850 & 0.190 & 0.413 & 0.774 & 0.140 \\
\hline ATT \% & $2.3 \%$ & $2.3 \%$ & $1.6 \%$ & $4.4 \%$ & $0.8 \%$ & $4.1 \%$ & $-0.4 \%$ & $4.0 \%$ & $-1.4 \%$ & $0.6 \%$ & $2.3 \%$ \\
\hline $\mathbf{N}^{\circ}$ of observations & 758,565 & 538,932 & 316,951 & 301,677 & 230,980 & 349,438 & 189,368 & 295,058 & 242,773 & 301,283 & 237,546 \\
\hline $\mathbf{N}^{\circ}$ of individuals & 152,015 & 116,859 & 71,764 & 64,997 & 51,735 & 77,269 & 43,599 & 64,252 & 55,541 & 65,885 & 51,552 \\
\hline Subsidy/Labor cost & $3.7 \%$ & $3.6 \%$ & $5.0 \%$ & $3.4 \%$ & $3.8 \%$ & $4.3 \%$ & $3.0 \%$ & $2.9 \%$ & $4.4 \%$ & $4.4 \%$ & $4.4 \%$ \\
\hline Elasticity & 0.632 & 0.647 & 0.311 & 1.302 & 0.217 & 0.941 & -0.119 & 1.387 & -0.321 & 0.120 & 0.634 \\
\hline Semi-Elasticity in $p p$ & 0.111 & 0.414 & 0.176 & 0.697 & 0.161 & 0.517 & -0.091 & 0.845 & -0.221 & 0.076 & 0.391 \\
\hline
\end{tabular}

\begin{tabular}{|c|c|c|c|c|c|c|c|c|c|c|c|}
\hline Women & $\begin{array}{l}\text { Overall } \\
\text { (1) }\end{array}$ & $\begin{array}{c}\text { Already } \\
\text { Working (2) }\end{array}$ & $\begin{array}{c}\text { Low Wage } \\
\text { (3) }\end{array}$ & $\begin{array}{c}\text { Manufacturing } \\
\text { Sector (4) }\end{array}$ & $\begin{array}{c}\text { Service } \\
\text { Sector (5) }\end{array}$ & $\begin{array}{l}\text { High Exit Rate } \\
\text { Committee (6) }\end{array}$ & $\begin{array}{l}\text { Low Exit Rate } \\
\text { Committee (7) }\end{array}$ & $\begin{array}{c}\text { Large Firms } \\
(8)\end{array}$ & $\begin{array}{c}\text { Small Firms } \\
\text { (9) }\end{array}$ & $\begin{array}{c}\text { Blue-collar } \\
(10)\end{array}$ & $\begin{array}{c}\text { White-collar } \\
\text { (11) }\end{array}$ \\
\hline ATT in $p p$ & 0.3 & 0.0 & -0.2 & 2.4 & -0.6 & 3.1 & -1.8 & 0.8 & -0.9 & -0.8 & 0.8 \\
\hline $95 \% \mathrm{Cl}$ & {$[-0.2 ; 0.8]$} & {$[-2.8 ; 2.8]$} & {$[-4.7 ; 4.2]$} & {$[-4.2 ; 9.0]$} & {$[-3.6 ; 2.4]$} & {$[-0.9 ; 7.1]$} & {$[-5.5 ; 1.9]$} & {$[-3.0 ; 4.6]$} & {$[-4.7 ; 2.9]$} & {$[-6.2 ; 4.6]$} & {$[-2.3 ; 3.9]$} \\
\hline Pvalue & 0.208 & 0.990 & 0.921 & 0.473 & 0.683 & 0.132 & 0.333 & 0.683 & 0.633 & 0.780 & 0.593 \\
\hline ATT \% & $4.0 \%$ & $0.3 \%$ & $-0.3 \%$ & $4.5 \%$ & $-0.8 \%$ & $5.2 \%$ & $-2.3 \%$ & $1.3 \%$ & $-1.2 \%$ & $-1.2 \%$ & $1.2 \%$ \\
\hline $\mathbf{N}^{\circ}$ of observations & 444,838 & 284,075 & 140,967 & 51,539 & 228,586 & 147,600 & 136,450 & 139,503 & 144,524 & 96,907 & 187,088 \\
\hline $\mathbf{N}^{\circ}$ of individuals & 88,835 & 61,923 & 33,543 & 11,077 & 50,034 & 33,538 & 30,178 & 30,435 & 33,064 & 22,502 & 39,780 \\
\hline Subsidy/Labor cost & $5.5 \%$ & $5.4 \%$ & $7.6 \%$ & $4.5 \%$ & $5.5 \%$ & $5.7 \%$ & $5.2 \%$ & $4.9 \%$ & $6.0 \%$ & $6.0 \%$ & $6.0 \%$ \\
\hline Elasticity & 0.717 & 0.005 & -0.044 & 1.010 & -0.155 & 0.901 & -0.452 & 0.258 & -0.201 & -0.176 & 0.197 \\
\hline Semi-Elasticity in $p p$ & 0.055 & 0.003 & -0.030 & 0.541 & -0.114 & 0.534 & -0.354 & 0.162 & -0.152 & -0.128 & 0.140 \\
\hline
\end{tabular}

WDiD on parallel growths: impact on the employment rate. Control group is 53.25-55.25 years old; treated group 58-59.5 years old. Effects on specific subpopulation (defined in q-7) by column: (1) Overall treated group, (2) Workers earning less than the treatment group median wage, (3) Workers in secondary sector, (4) Workers in tertiary sector, (5) Workers in sectoral industrial committees with an exit rate from employment above the median $(=18 \%)$, (6) Workers in sectoral industrial committees with an exit rate below the median, (7) Workers in firms with at least 200 employees, (8) Workers in firms with less than 200 employees, (9) Blue-collar workers, (10) White-collar workers. Point estimates of the ATT are expressed in percentage points $(p p)$, in proportional (\%) changes in the employment rate and in terms of (semi-)elasticity, i.e. the proportional (pp) effect on the employment rate of a proportional reduction in the labour costs. $N^{\circ}$ of observations is the sum of the number of individuals observed in each quarter of the analysis. Standard errors are obtained by a stratified bootstrap (clustering by individual) with 200 repetitions and $95 \%$ confidence intervals (CI) by assuming normality. ${ }^{* * *}$ : significant at 1\%, **: significant at 5\%, *: significant at $10 \%$. 
Table 4: Impact on the Share in Early Retirement and Other Non-Employment States

\begin{tabular}{|c|c|c|c|c|}
\hline \multirow[t]{2}{*}{ Men } & \multicolumn{2}{|c|}{ Manufacturing Sector } & \multicolumn{2}{|c|}{ High Exit Rate Committee } \\
\hline & Bridge pension (1) & Other Exit (2) & Bridge pension (3) & Other Exit (4) \\
\hline ATT in pp & $-2.1 * *$ & -0.4 & $-3.7^{* * *}$ & 1.1 \\
\hline $95 \% \mathrm{Cl}$ & {$[-3.8 ;-0.4]$} & {$[-2.3,1.5]$} & {$[-5.1 ;-2.3]$} & {$[0.6,2.8]$} \\
\hline Pvalue & 0.048 & 0.695 & 0.000 & 0.195 \\
\hline ATT \% & $-5.8 \%$ & $-3.6 \%$ & $-10.3 \%$ & $12.1 \%$ \\
\hline $\mathrm{N}^{\circ}$ of observations & 301,678 & 301,678 & 349,436 & 349,436 \\
\hline $\mathbf{N}^{\circ}$ of individuals & 64,997 & 64,997 & 77,269 & 77,269 \\
\hline
\end{tabular}

\begin{tabular}{|c|c|c|c|c|}
\hline \multirow[t]{2}{*}{ Women } & \multicolumn{2}{|c|}{ Manufacturing Sector } & \multicolumn{2}{|c|}{ High Exit Rate Committee } \\
\hline & Bridge pension (1) & Other Exit (2) & Bridge pension (3) & Other Exit (4) \\
\hline ATT in $p p$ & 3.5 & - & -0.9 & -1.9 \\
\hline $95 \% \mathrm{Cl}$ & {$[-0.2 ; 6.9]$} & - & {$[-5.1 ;-2.3]$} & {$[-5.4,1.4]$} \\
\hline Pvalue & 0.225 & - & 0.495 & 0.259 \\
\hline ATT \% & $12.5 \%$ & - & $-3.9 \%$ & $-11.3 \%$ \\
\hline $\mathrm{N}^{\circ}$ of observations & 51,539 & - & 147,600 & 147,600 \\
\hline $\mathrm{N}^{\circ}$ of individuals & 11,077 & - & 33,538 & 33,538 \\
\hline
\end{tabular}

WDiD on parallel growths: impact on the share of people in pre-retirement/bridge pension (columns 1, 3) and in any other non-employment status (column 2,4) for the subpopulations for which a significant employment effect was estimated. Control group 53.25-55.25 years old; treated group 58-59.5 years old. Effects on specific subpopulation (defined in q-7) by column: (1 and 2) Workers in manufacturing sector, (3-4) Workers in sectoral industrial committees with high exit rate from employment. ATT are expressed in percentage points (pp) and percentage (\%) changes. Estimates are not reported for the "other exit" outcome of women in the manufacturing sector since they are very noisy and not following a parallel path or growths. $N^{\circ}$ of observations is the sum of the number of individuals observed in each quarter of the analysis. Standard errors are obtained by a stratified bootstrap (clustering by individual) with 200 repetitions and 95\% confidence intervals (CI) by assuming normality. ${ }^{* * *}$ : significant at $1 \%, * *$ : significant at $5 \%, *$ : significant at $10 \%$.

In Table 4 we report further evidence that the positive employment effects are caused by a lower rate of entry into the bridge pension, at least for men. We observe that for men employed in the manufacturing sector or in a firm at high risk of early retirement the share in early retirement significantly decreases, while the share in other non-employment states is not significantly affected. For women, we do not find any effect that is significantly different from zero. This mirrors the imprecisely estimated effect on the employment rate. Hence, our data do not allow finding reliable estimates for women. ${ }^{39}$

Finally, we do not find any significant effect on employment for any of the other subpopulations that we considered, even not for low-wage workers, suggesting that the pay-productivity gap is present for this group as well. These results are therefore largely in accordance with the hypotheses that we formulated, as well as with the existing scientific evidence.

\subsection{Effect on the Hours Worked}

Table 5 reports the impact on employment at the intensive margin. Since no subsidy is granted to employees working less than $33 \%$ of a full-time worker within a quarter, employers have incentives to increase the working time of the subgroup of individuals for whom the marginal productivity exceeds marginal costs. In line with this prediction the subsidy significantly reduces the number of men working less than $30 \%$ of a full-time by $13 \%$, but since only few men are contained in this category,

\footnotetext{
${ }^{39}$ The estimates for the "other exit" outcome in the manufacturing sector are not reported since they are very noisy. Placebo tests reject the assumption of parallel path and at the same time the parallel growths assumption is unrealistic.
} 
this decreases the share of men in this category by only $0.6 p p$. In contrast, more women are working in this category. Consequently, even if the point estimate in $p p$ is similar to that for men $(-0.5 p p)$, the subsidy reduces the number of women in this category by only $4 \%$, an effect that is not significantly different from zero. This contrasting evidence for men and women may be related to the lower supply elasticity of these specific women, who, more than men, may have deliberately chosen to work few hours as a consequence of the traditional gender division in caring responsibilities in the household. The subsidy essentially shifts men working less than $30 \%$ of a full-time to more than $80 \%$ (even if the latter effect is not significant). For women the subsidy significantly decreases the share of women in the category $30 \%$ to $80 \%$ of a full-time by $1.2 \mathrm{pp}$ in favour of the category working more than $80 \%$. In Section 4 we argued that the subsidy should especially affect the working time of individuals with an elastic labour supply, such as for workers who in the absence of the subsidy are encouraged by the time credit scheme to work part-time ( $50 \%$ or $80 \%$ of a full-time). The findings reported in Table 6 confirm that the subsidy seems to have induced firms to discourage their employees to reduce their working time within the time credit scheme, especially for women, who are also more intensive users of this scheme (see Section 2).

For men, the effect on the intensive margin is stronger for the sub-populations for which we estimated statistically significant effects on the employment rate. This suggests that for men the statistically significant impacts at the intensive margin may reflect compositional effects, i.e. that the employment gain at the extensive margin especially concerned full-time workers. The gain at the extensive margin is likely to have increased the share of employees working between $30 \%$ and $80 \%$ of a full-time. This can explain why the effect at the intensive margin is not significantly negative for this category, while Table 6 does report a significant decrease in the use of time credit for men. By contrast, for women, for whom we did not find employment effects at the extensive margin significantly different from zero, more positive effects on working time are observed, especially in the service sector and in large firms. This is consistent with access to time credit schemes being less restrictive in large firms (see Section 2 - in the pre-treatment period 21\% of the women working in large firms was in time-credit, compared to $4 \%$ in small firms) and more used in the service sector ( $12 \%$ of the women working in the service sector was in time credit, compared to $7 \%$ in the manufacturing sector), increasing thereby the labour supply elasticity of these women.

Based on the approximate fraction of working time (see footnote 20) we calculate the corresponding employment elasticities of the wage cost subsidy at the intensive margin. These elasticities are reported in the last two rows of Table 5 . Overall, even if we do find significantly positive effects on the number of hours worked, the corresponding employment elasticities are small, irrespectively of the considered subpopulation. On average this elasticity is 0.13 for men and 0.28 for women. 
Table 5: Impact on the Hours Worked (Intensive Margin)

\begin{tabular}{|c|c|c|c|c|c|c|c|c|c|c|}
\hline Men & Overall (1) & Low Wage (2) & Manufacturing Sector (3) & Service Sector (4) & High Exit Rate (5) & Low Exit Rate (6) & \begin{tabular}{|l|} 
Large Firms (7) \\
\end{tabular} & Small Firms (8) & Blue-collar (9) & White-collar (10) \\
\hline $0 \%-30 \%$ : ATT in $p p$ & $-0.6 * * *$ & $-0.5^{* *}$ & $-0.4^{* *}$ & $-0.6^{* * *}$ & $-0.8^{* * *}$ & -0.2 & $-0.4^{* * *}$ & $-0.6^{* *}$ & $-0.8^{* *}$ & 0.1 \\
\hline $95 \% \mathrm{Cl}$ & {$[-0.9 ;-0.2]$} & {$[-1.0 ;-0.1]$} & {$[-0.8 ;-0.1]$} & {$[-1.0 ;-0.2]$} & {$[-1.3 ;-0.3]$} & {$[-0.6 ; 0.2]$} & {$[-0.7 ;-0.2]$} & {$[-1.1 ;-0.1]$} & {$[-1.4 ;-0.2]$} & {$[-0.2 ; 0.3]$} \\
\hline Pvalue & 0.001 & 0.029 & 0.018 & 0.005 & 0.002 & 0.423 & 0.002 & 0.016 & 0.011 & 0.605 \\
\hline ATT in \% & $-13.4 \%$ & $-9.1 \%$ & $-14.7 \%$ & $-12.7 \%$ & $-15.3 \%$ & $-9.6 \%$ & $-21.7 \%$ & $-9.8 \%$ & $-11.5 \%$ & $6.4 \%$ \\
\hline $31 \%-80 \%:$ ATT in $p p$ & 0.0 & -0.3 & -0.7 & 0.1 & -0.7 & 0.3 & 0.1 & -0.3 & -0.2 & -0.2 \\
\hline $95 \% \mathrm{Cl}$ & {$[-0.7 ; 0.7]$} & {$[-1.3 ; 0.7]$} & {$[-1.7 ; 0.3]$} & {$[-0.9 ; 1.1]$} & {$[-1.6 ; 0.2]$} & {$[-0.9 ; 1.5]$} & {$[-0.8 ; 1.0]$} & {$[-1.2 ; 0.7]$} & {$[-1.3 ; 0.9]$} & {$[-1.1 ; 0.6]$} \\
\hline Pvalue & 1.000 & 0.576 & 0.183 & 0.790 & 0.118 & 0.625 & 0.803 & 0.569 & 0.658 & 0.584 \\
\hline ATT in \% & $0.0 \%$ & $-1.4 \%$ & $-4.5 \%$ & $0.8 \%$ & $-3.9 \%$ & $2.1 \%$ & $0.8 \%$ & $-1.4 \%$ & $-1.1 \%$ & $-2.0 \%$ \\
\hline$>80 \%:$ ATT in $p p$ & 0.6 & $0.8^{*}$ & $1.1^{* *}$ & 0.4 & $1.5^{* * *}$ & -0.1 & 0.3 & $0.9^{*}$ & $1.0^{*}$ & 0.2 \\
\hline $95 \% \mathrm{Cl}$ & {$[-0.1 ; 1.2]$} & {$[-0.1 ; 1.8]$} & {$[0.1 ; 2.2]$} & {$[-0.5 ; 1.4]$} & {$[0.6 ; 2.4]$} & {$[-1.3 ; 1.1]$} & {$[-0.7 ; 1.3]$} & {$[-0.1 ; 1.9]$} & {$[-0.1 ; 2.1]$} & {$[-0.7 ; 1.1]$} \\
\hline Pvalue & 0.103 & 0.088 & 0.036 & 0.366 & 0.001 & 0.839 & 0.518 & 0.073 & 0.064 & 0.697 \\
\hline ATT in \% & $0.7 \%$ & $1.1 \%$ & $1.4 \%$ & $0.6 \%$ & $2.0 \%$ & $-0.1 \%$ & $0.4 \%$ & $1.2 \%$ & $1.4 \%$ & $21.2 \%$ \\
\hline ATT total hours $\%$ & $0.5 \% * *$ & $0.5 \% *$ & $0.7 \%^{* * *}$ & $0.4 \%$ & $1.1 \%^{* * *}$ & $0.0 \%$ & $0.2 \%$ & $0.7 \%^{* *}$ & $0.8 \% * *$ & $0.0 \%$ \\
\hline $95 \% \mathrm{Cl}$ & {$[0.0 ; 0.9]$} & {$[0.0 ; 1.2]$} & {$[0.1 ; 1.2]$} & {$[-0.2 ; 1.0]$} & {$[0.4 ; 1.7]$} & {$[-0.6 ; 0.6]$} & {$[-0.3 ; 0.8]$} & {$[0.1 ; 1.3]$} & {$[0.1 ; 1.5]$} & {$[-0.4 ; 0.4]$} \\
\hline Elasticity & 0.128 & 0.121 & 0.196 & 0.107 & 0.245 & 0.005 & 0.099 & 0.158 & 0.165 & 0.006 \\
\hline $\mathbf{N}^{\circ}$ of observations & 433,373 & 266,378 & 227,946 & 200,287 & 255,441 & 150,242 & 231,979 & 201,387 & 216,985 & 186,156 \\
\hline $\mathrm{N}^{\circ}$ of individuals & 98,899 & 61,784 & 51,504 & 47,250 & 59,422 & 36,361 & 53,673 & 48,140 & 49,869 & 43,032 \\
\hline Women & Overall (1) & Low Wage (2) & Manufacturing Sector (3) & Service Sector (4) & High Exit Rate (5) & Low Exit Rate (6) & \begin{tabular}{|l|} 
Large Firms (7) \\
\end{tabular} & Small Firms (8) & Blue-collar (9) & White-collar (10) \\
\hline 0\%-30\%: ATT in $p p$ & -0.5 & -0.5 & 0.4 & $-0.7^{*}$ & -0.8 & 0.0 & $-0.8^{* *}$ & -0.4 & -0.2 & -0.4 \\
\hline $95 \% \mathrm{Cl}$ & {$[-1.2 ; 0.2]$} & {$[-1.5 ; 0.6]$} & {$[-1.2 ; 2.1]$} & {$[-1.4 ; 0.0]$} & {$[-1.8 ; 0.2]$} & {$[-0.7 ; 0.6]$} & {$[-1.7 ; 0.0]$} & {$[-1.4 ; 0.5]$} & {$[-1.7 ; 1.3]$} & {$[-0.9 ; 0.2]$} \\
\hline Pvalue & 0.131 & 0.369 & 0.612 & 0.066 & 0.111 & 0.910 & 0.046 & 0.396 & 0.765 & 0.217 \\
\hline ATT in \% & $-3.9 \%$ & $-2.5 \%$ & $4.6 \%$ & $-5.0 \%$ & $-5.4 \%$ & $-0.5 \%$ & $-12.5 \%$ & $-2.2 \%$ & $-0.9 \%$ & $-7.3 \%$ \\
\hline 31\%-80\%: ATT in $p p$ & $-1.2 * *$ & $-1.9^{* *}$ & -0.1 & $-1.2^{* *}$ & -0.5 & $-1.9^{* * *}$ & $-1.9^{* *}$ & -0.8 & -1.0 & $-1.3^{* *}$ \\
\hline $95 \% \mathrm{Cl}$ & {$[-2.1 ;-0.2]$} & {$[-3.4 ;-0.3]$} & {$[-2.9 ; 2.7]$} & {$[-2.4 ;-0.1]$} & {$[-2.0 ; 1.0]$} & {$[-3.2 ;-0.5]$} & {$[-3.3 ;-0.4]$} & {$[-2.1 ; 0.6]$} & {$[-3.0 ; 1.0]$} & {$[-2.6 ;-0.1]$} \\
\hline Pvalue & 0.015 & 0.022 & 0.950 & 0.037 & 0.497 & 0.005 & 0.011 & 0.254 & 0.313 & 0.036 \\
\hline ATT in \% & $-2.6 \%$ & $-3.5 \%$ & $-0.2 \%$ & $-2.6 \%$ & $-1.0 \%$ & $-4.1 \%$ & $-3.6 \%$ & $-1.9 \%$ & $-2.0 \%$ & $-3.0 \%$ \\
\hline$>80 \%:$ ATT in $p p$ & $1.7^{* * *}$ & $2.3^{* * *}$ & -0.3 & $1.9^{* * *}$ & $1.3^{* *}$ & $1.9^{* * *}$ & $2.7^{* * *}$ & $1.2^{* *}$ & 1.2 & $1.7^{* * *}$ \\
\hline $95 \% \mathrm{Cl}$ & {$[0.8 ; 2.6]$} & {$[1.0 ; 3.7]$} & {$[-3.1 ; 2.4]$} & {$[0.9 ; 2.9]$} & {$[0.0 ; 2.7]$} & {$[0.8 ; 3.0]$} & {$[1.4 ; 4.1]$} & {$[0.0 ; 2.4]$} & {$[-0.3 ; 2.8]$} & {$[0.5 ; 2.9]$} \\
\hline Pvalue & 0.000 & 0.001 & 0.812 & 0.000 & 0.049 & 0.001 & 0.000 & 0.047 & 0.119 & 0.004 \\
\hline ATT in \% & $4.3 \%$ & $8.5 \%$ & $-0.6 \%$ & $4.9 \%$ & $3.7 \%$ & $4.1 \%$ & $6.6 \%$ & $3.1 \%$ & $5.3 \%$ & $3.4 \%$ \\
\hline ATT total hours $\%$ & $1.5 \% * * *$ & $2.3 \% * * *$ & $0.6 \%$ & $1.7 \% * * *$ & $1.5 \%^{* *}$ & $1.2 \%^{* * *}$ & $2.1 \%^{* * *}$ & $1.4 \%^{* *}$ & $1.9 \% *$ & $1.1 \%^{* * *}$ \\
\hline $95 \% \mathrm{Cl}$ & {$[0.7 ; 2.4]$} & {$[1.1 ; 3.5]$} & {$[-1.5 ; 2.7]$} & {$[0.9 ; 2.5]$} & {$[0.4 ; 2.7]$} & {$[0.3 ; 2.1]$} & {$[1.0 ; 3.1]$} & {$[0.2 ; 2.5]$} & {$[0.0 ; 3.8]$} & {$[0.3 ; 1.8]$} \\
\hline Elasticity & 0.280 & 0.302 & 0.124 & 0.302 & 0.262 & 0.240 & 0.416 & 0.219 & 0.243 & 0.223 \\
\hline $\mathbf{N}^{\circ}$ of observations & 224,284 & 104,255 & 36,457 & 184,959 & 102,682 & 102,657 & 107,646 & 116,432 & 65,313 & 139,865 \\
\hline $\mathbf{N}^{\circ}$ of individuals & 53,299 & 26,224 & 8,621 & 44,006 & 25,354 & 24,424 & 25,782 & 28,568 & 16,401 & 32,486 \\
\hline
\end{tabular}

WDiD on parallel path: impact on the intensive margin defined as number of workers with a certain working time with respect to the reference time (0-30\%, 31-80\%, $>81 \%)$. Control group is 53.25-55.25 years old; treated group 58sector, (5) Workers in sectoral industrial committees with an exit rate from employment above the median (=18\%), (6) Workers in sectoral industrial committees with an exit rate below the median, (7) Workers in firms with at least 200 employees, (8) Workers in firms with less than 200 employees, (9) Blue-collar workers, (10) White-collar workers. The elasticity approximates the working time elasticity of the wage cost subsidy (see footnote 20). Standard errors are obtained by a stratified bootstrap (clustering by individual) with 200 repetitions and $95 \%$ confidence intervals (CI) by assuming normality. ${ }^{* * *}$ : significant at $1 \%,{ }^{* *}$ : significant at $5 \%$, *: significant at $10 \%$. 
Table 6: Impact on the Time-Credit

\begin{tabular}{|c|c|c|c|c|c|c|}
\cline { 2 - 7 } \multicolumn{1}{c|}{} & \multicolumn{2}{c|}{ Overall sample (1) } & \multicolumn{2}{c|}{ High Exit Rate (2) } & \multicolumn{2}{c|}{ Low Exit Rate (3) } \\
\hline & Men & Women & Men & Women & Men & Women \\
\hline ATT pp & $-0.7 * * *$ & $-1.2^{* * *}$ & $-2.0 * * *$ & $-1.3^{* * *}$ & 0.3 & $-0.9^{*}$ \\
\hline CI & {$[-1.2 ;-0.2]$} & {$[-1.8 ;-0.5]$} & {$[-2.7,-1.4]$} & {$[-2.2,-0.3]$} & {$[-0.4,1.1]$} & {$[-1.93,0.6]$} \\
\hline Pvalue & 0.003 & 0.000 & 0.000 & 0.008 & 0.369 & 0.065 \\
\hline ATT \% & $-9.8 \%$ & $-8.0 \%$ & $-32.8 \%$ & $-9.6 \%$ & $4.0 \%$ & $-5.8 \%$ \\
\hline N Observations & 433,373 & 224,284 & 59,406 & 25,347 & 36,346 & 24,400 \\
\hline N clusters & 98,899 & 53,299 & 255,398 & 102,659 & 150,205 & 102,577 \\
\hline
\end{tabular}

WDiD on parallel path: impact on the share of people in part-time time-credit for the overall employed sample. Control group is $53.25-55.25$ years old; treated group 58-59.5 years old. Effects on specific subpopulation (defined in time q) by column: (1) Overall treated group, (2) Workers in sectoral industrial committees with an exit rate from employment above the median (=18\%), (3) Workers in sectoral industrial committees with an exit rate below the median. $N^{\circ}$ of observations is the sum of the number of individuals observed in each quarter of the analysis. Standard errors are obtained by a stratified bootstrap (clustering by individual) with 200 repetitions and $95 \%$ confidence intervals (Cl) by assuming normality. ${ }^{* * *}$ : significant at $1 \%, * *$ : significant at $5 \%, *$ : significant at $10 \%$.

\subsection{Effect on the Hourly Wage}

In Section 4 we argued that in the short run we do not expect the reduction of employers' SSC to have any impact on gross wages (net of employers' SSC) and, consequently, neither on the net wage. In Table A.2 in the Appendix we report the ATT of the wage cost subsidy on gross wages. In line with this hypothesis, the gross wage elasticity of the wage cost subsidy is small and never statistically significant at the $5 \%$ level. The overall point estimates of the elasticity are -0.09 for men and 0.02 for women. This is not a consequence of a lack of precision. Even at the upper bound of the $95 \%$ confidence interval it is small, respectively 0.270 and 0.137 . One could criticize these results on the grounds that they do not take the Heckman's (1974) selection bias into account. If the wage cost subsidy saved selective jobs in terms of hourly wage, then this could bias our findings. However, we did not find that the impact of the subsidy on the employment rate was higher for low-wage workers.

\subsection{Substitution and Anticipatory effects}

In a sensitivity analysis we considered a wider control group, containing workers who are closer to the age eligibility threshold of 58 years. This control group contains workers from age 53.25 up to 57 rather than up to 55.25 as in the baseline analysis. The impact of the wage cost subsidy is found to be robust on the hours worked and the hourly gross wage. However, the effects on employment are found to be stronger when we consider employment at the extensive margin as outcome (see summary tables in Appendix A2). This suggests that the reduction of wage costs for older workers induces employers to substitute older for younger workers. In Section 4.3 we indeed argued that the Canada Dry early retirement system makes it possible for firms to push younger instead of older workers into early retirement. This also implies that the baseline analysis might overestimate the net effect of the wage cost subsidy on the employment rate, since at least part of the positive effects would then come at the expense of employment of younger workers. 


\subsection{Cost-Benefit Analysis (CBA)}

To get an idea of the welfare benefits or costs involved, we report a CBA for two scenarios. We calculate the effect of the subsidy on three indicators, all measured per job saved by the policy:

(i) Gross budgetary cost: average cost of the subsidy for the state before any behavioural impact;

(ii) Net budgetary cost: average cost of the subsidy for the state, net of savings for the public budget, i.e. tax revenues (income tax and contributions to social security) generated by the jobs that were saved by the policy, ${ }^{40}$ as well as the outlays that the government would have spent in the absence of the policy, mostly on allowances to the early retirees (at the extensive margin) or to participants in the time-credit scheme (at the intensive margin);

(iii) Welfare gain (or cost) for society: the gain in terms of the production generated by these saved jobs minus the efficiency cost ("excess burden" or "deadweight loss") of the net budgetary expenditures mentioned in (ii). To calculate this efficiency cost we multiply the effect on government budget by the Marginal Cost of Public Funds (MCF) minus one. ${ }^{41}$ For Belgium a MCF equal to two is considered to be appropriate (Kleven and Kreiner 2006; Barrios Cobos et al. 2013). The value of production is adjusted for the pay-productivity gap. As Vandenberghe et al. (2013) estimate this gap for the age class $58-59.5$ to be $15.7 \%$, the labour costs are multiplied by 0.843 .

We follow Staubli and Zweimüller (2013) by estimating the two building blocks of these indicators (the net budgetary cost for the state and the saved production) in exactly the same way as we estimate the baseline ATT for the outcome variables of interest, i.e. by a trend-adjusted WDiD on the values of these indicators for each individual retained in the analysis. ${ }^{42}$ We do this analysis separately for the workers in sectoral industrial committees with a high and a low risk of exiting employment and subsequently aggregate up the results. In the CBA we ignore a number of components, because they are difficult to measure. We overestimate the benefit for society by (i) not counting the opportunity cost of working for the saved jobs, (ii) not taking into account that the estimated employment effects may be biased upwards through substitution of individuals in the control group by eligible older workers (Section 4.3 and 7.4), and (iii) not taking into account that in about $43 \%$ of the industrial committees firms using early-retirement schemes are obliged to replace early retirees by unemployed workers (Section 2 and 4.3). We also ignore the potential distributional and health impacts of the subsidy. It is a priori unclear in which direction the latter neglect biases our CBA.

\footnotetext{
${ }^{40}$ Since information on personal income taxes and personal SSC is missing in our data, we approximate this by multiplying the wage cost by 0.567 , i.e. the average tax wedge in 2001 (OECD, 2007).

${ }^{41}$ The net budgetary cost of the policy is not, in se, a cost to society, since it just involves transfers between individuals.

${ }^{42}$ Staubli and Zweimüller (2013) only consider the effect on the budgetary cost, not on saved production, since they do not calculate the welfare gain (cost) for society. In these estimations we ignore allowances for those entering statutory early retirement, sickness and disability and the productivity of self-employed workers. However, since only $1.1 \%$ of the relevant sub-sample is entitled to these allowances and only $0.9 \%$ is self-employed, this only introduces a slight bias.
} 
Table 7: Cost-Benefit Analysis

\begin{tabular}{|c|c|c|c|}
\cline { 2 - 4 } \multicolumn{1}{c|}{} & \multicolumn{3}{c|}{ 2002 subsidy (1) } \\
\hline Gross budgetary cost per saved job & Overall & Men & Women \\
\hline Net budgetary cost per saved job & $€ 5,993$ & $€ 6,617$ & $€ 4,673$ \\
\hline Net cost to society per saved job & $€ 32,788$ & $€ 3,242$ & $€ 1,829$ \\
\hline
\end{tabular}

\begin{tabular}{|c|c|c|c|}
\cline { 2 - 4 } \multicolumn{1}{c|}{} & \multicolumn{3}{c|}{ Targeted subsidy (2) } \\
\hline Gross budgetary cost per saved job & Overall & Men & Women \\
\hline Net budgetary cost per job & $€ 2,805$ & $€ 3,204$ & $€ 1,961$ \\
\hline Net cost to society per saved job & $-€ 2,083$ & $€ 696$ & $-€ 410$ \\
\hline
\end{tabular}

Monthly costs (benefits if negative) in 2004 euros per saved job. (1) Cost-benefit analysis for the SSC exemption on all the individuals (58-59.5 years old) from the second quarter of 2002 until the second quarter of 2003; (2) Cost-benefit analysis in the counterfactual of a policy targeting the subsidy to the high-exit flow sectoral industrial committees. Control units are 53.25-55.25 years old. Gross cost per saved job is the total cost of the wage cost subsidy divided by the number of saved jobs. Net cost per saved job is estimated by a trend adjusted WDiD on the individual net budgetary gross cost of the policy divided by the number of saved jobs. The net cost to society is the efficiency cost of public funds minus the value of production generated by the jobs that were saved by reduction in SSC. The latter is estimated by trend adjusted WDiD on the individual gross wage costs multiplied by 0.843 to account for the pay-productivity gap. The CBA ignores potential substitution and anticipation effects. The costs to society ignore the value of leisure, the potential distributional and health impacts of the measure, and the potential benefits in the absence of the subsidy that some of the early retirees would be replaced by unemployed workers.

In Table 7 we report the outcome of our CBA. We perform the CBA for two cases. In the first case the subsidy is, as in reality, granted both to the high and the low-exit sectoral industrial committees. In the second hypothetical case the subsidy is targeted to the high-exit sectoral industrial committees. Overall the wage cost subsidy targeted to older workers is clearly an expensive policy that fails the cost-benefit test. The gross cost per saved job is nearly $€ 6,000$ and the net cost remains as high as $€ 2,800$. The net cost to society is $€ 326$. Since, as higher mentioned, a number of costs have been ignored in the calculations, this is likely a lower bound. For women we find a net benefit of €990 for society. This is because the point estimate of the ATT of the subsidy on the employment rate is higher for women than for men (Table 3). However, this finding should be interpreted cautiously, since this ATT was not statistically significantly different from zero.

Our findings strongly suggest that effectiveness could be enhanced if the target group of the subsidy could be further narrowed down to workers at high risk of exit to early retirement. Indeed in case the subsidy would have been targeted to high-exit sectoral industrial committees, the gross and net cost of the subsidy would only have been about $€ 2,800$ and $€ 340$, while society would gain about $€ 2,080$ per saved job. Even if this gain is overestimated, it is substantial and, hence, likely to remain positive if the ignored costs would be taken into account. However, such a targeting of the subsidy would breach the EU fair competition law. Furthermore, raising the early retirement age seems a much cheaper alternative policy measure to achieve the same effect (see e.g. Staubli and Zweimüller, 2013). However, this assumes that the employer will not dismiss workers if the option of early retirement is no longer available. Due to the important pay-productivity gap for older workers in Belgium, this is a strong assumption. In addition, delaying the age of early retirement increases the cost of using deferred compensation schemes as incentive device (Lazear, 1979). In sum, further research is required to determine the best strategy for retaining older workers in the labour force. 


\section{Conclusion}

This paper studies the effect of a wage subsidy targeted to older workers on employment, working time and hourly wage. In the last years several OECD countries have implemented such measures to postpone the retirement of older workers. However, evidence on the effectiveness of such policies is scarce. Our research provides new evidence by estimating the impact of an automatic $€ 400$ quarterly reduction of employers' Social Security Contributions (SSC) introduced in Belgium in 2002.

Based on a large sample of 243,655 older individuals for whom we could observe using administrative registers the labour market history from as early as 1957, we estimate the effect of this wage cost subsidy on the employment rate, working time and hourly wage. In order to enhance the precision of our estimates, the sample was endogenously stratified such that entries in and exits from private sector employment were over-represented. By comparing the evolution of outcome variables for eligible older workers to non-eligible younger workers we could identify the Average Treatment effect on the Treated (ATT) of this policy measure. More precisely, we implemented a Conditional Differencein-Differences (CDiD) estimator by Inverse Probability Weighting (IPW) which we adjusted to accommodate for the endogenous sampling. In addition, to allow for an age related shock at 58, induced by the legal possibility of entering early retirement, we used this weighted DiD estimator in a multiple repeated cross-sections framework, where we kept the age fixed over time rather than the individual, as in a panel framework. We conducted placebo tests on pre-treatment data and, in case of rejection, proposed a parametric trend-adjusted weighted DiD estimator.

In line with the scarce literature, we find that the wage cost subsidy has only a small impact on employment, both at the intensive and extensive margin and that the hourly gross wage is not significantly affected. As predicted by our theoretical model, the subsidy seems to be more effective for workers at risk of leaving the labour market and enter early retirement. Nevertheless, this result requires some qualification, since we find evidence that it may partly reflect a substitution of older for younger workers. Overall, the policy reform does not pass the cost-benefit test. If the subsidy could have been targeted at sectoral industrial committees in which the risk of early retirement is high, then this conclusion is reversed. However, it is not clear whether there is a legal basis for such refinement of the target population. In addition, increasing the age of early retirement seems to be a cheaper policy alternative that could achieve similar effects. However, this hinges on the assumption that employers would then not dismiss these workers. Whether this assumption is realistic may depend on the institutional context and is matter for future research. 


\section{Appendix}

Table A.1: Descriptive Statistics for the Treatment and Control Groups in the Baseline Model

\begin{tabular}{|c|c|c|c|c|c|c|c|}
\hline & & \multicolumn{3}{|c|}{ Men } & \multicolumn{3}{|c|}{ Women } \\
\hline & & \multicolumn{2}{|c|}{ Mean } & \multirow{2}{*}{$\begin{array}{c}\begin{array}{c}\text { t-test } \\
\text { Mean } \\
\text { equality }\end{array} \\
p>|t|\end{array}$} & \multicolumn{2}{|c|}{ Mean } & \multirow{2}{*}{$\begin{array}{c}\text { t-test } \\
\text { Mean } \\
\text { equality } \\
p>|t|\end{array}$} \\
\hline & Variable & Treated & Control & & Treated & Control & \\
\hline \multirow{11}{*}{ Province } & Brussels & $7.67 \%$ & $7.13 \%$ & 0.099 & $8.42 \%$ & $8.38 \%$ & 0.936 \\
\hline & Antwerp & $17.06 \%$ & $16.10 \%$ & 0.033 & $16.94 \%$ & $16.65 \%$ & 0.646 \\
\hline & Flemish Brabant & $10.64 \%$ & $10.50 \%$ & 0.719 & $10.53 \%$ & $10.56 \%$ & 0.952 \\
\hline & West Flanders & $12.94 \%$ & $10.94 \%$ & 0.000 & $12.17 \%$ & $10.60 \%$ & 0.003 \\
\hline & East Flanders & $14.50 \%$ & $13.43 \%$ & 0.012 & $13.91 \%$ & $13.58 \%$ & 0.571 \\
\hline & Limburg & $8.11 \%$ & $8.04 \%$ & 0.849 & $7.62 \%$ & $7.20 \%$ & 0.342 \\
\hline & Walloon Brabant & $3.75 \%$ & $3.69 \%$ & 0.804 & $3.55 \%$ & $3.90 \%$ & 0.248 \\
\hline & Hainaut & $11.26 \%$ & $13.31 \%$ & 0.000 & $11.04 \%$ & $12.95 \%$ & 0.000 \\
\hline & Liège & $8.54 \%$ & $10.27 \%$ & 0.000 & $9.89 \%$ & $10.12 \%$ & 0.636 \\
\hline & Luxembourg & $1.70 \%$ & $2.20 \%$ & 0.008 & $1.93 \%$ & $1.83 \%$ & 0.679 \\
\hline & Namur & $3.84 \%$ & $4.39 \%$ & 0.035 & $4.03 \%$ & $4.23 \%$ & 0.540 \\
\hline \multirow{3}{*}{ Nationality } & Belgian & $92.61 \%$ & $92.59 \%$ & 0.948 & $94.14 \%$ & $94.52 \%$ & 0.330 \\
\hline & EU & $6.03 \%$ & $6.28 \%$ & 0.405 & $4.54 \%$ & $4.22 \%$ & 0.342 \\
\hline & Others & $1.36 \%$ & $1.13 \%$ & 0.111 & $1.32 \%$ & $1.26 \%$ & 0.783 \\
\hline \multirow{5}{*}{ Household composition } & Single & $12.55 \%$ & $12.82 \%$ & 0.526 & $13.08 \%$ & $11.00 \%$ & 0.000 \\
\hline & Single with children & $1.67 \%$ & $2.46 \%$ & 0.000 & $5.39 \%$ & $7.58 \%$ & 0.000 \\
\hline & Couple & $31.58 \%$ & $45.77 \%$ & 0.000 & $23.75 \%$ & $36.58 \%$ & 0.000 \\
\hline & Couple with children & $48.66 \%$ & $33.15 \%$ & 0.000 & $48.78 \%$ & $39.15 \%$ & 0.000 \\
\hline & other & $5.54 \%$ & $5.81 \%$ & 0.384 & $9.00 \%$ & $5.70 \%$ & 0.000 \\
\hline \multirow{5}{*}{ Household size } & 1 & $13.25 \%$ & $13.32 \%$ & 0.868 & $13.89 \%$ & $10.70 \%$ & 0.000 \\
\hline & 2 & $45.08 \%$ & $29.90 \%$ & 0.000 & $50.55 \%$ & $39.42 \%$ & 0.000 \\
\hline & 3 & $24.66 \%$ & $27.71 \%$ & 0.000 & $23.30 \%$ & $28.75 \%$ & 0.000 \\
\hline & 4 & $11.03 \%$ & $19.39 \%$ & 0.000 & $8.59 \%$ & $14.81 \%$ & 0.000 \\
\hline & $5+$ & $5.98 \%$ & $9.69 \%$ & 0.000 & $3.67 \%$ & $6.32 \%$ & 0.000 \\
\hline \multirow{2}{*}{ Household members } & Below18 years old & $9.01 \%$ & $19.15 \%$ & 0.000 & $4.55 \%$ & $11.57 \%$ & 0.000 \\
\hline & Above 65 years old & $5.11 \%$ & $5.97 \%$ & 0.003 & $8.58 \%$ & $6.02 \%$ & 0.000 \\
\hline \multirow{6}{*}{ Primary status $7 \mathrm{q}$ earlier } & Private sector employee & $25.42 \%$ & $37.61 \%$ & 0.000 & $10.25 \%$ & $17.70 \%$ & 0.000 \\
\hline & Inactive & $38.60 \%$ & $21.23 \%$ & 0.000 & $65.93 \%$ & $54.05 \%$ & 0.000 \\
\hline & Unemployed & $1.70 \%$ & $2.06 \%$ & 0.018 & $2.42 \%$ & $3.33 \%$ & 0.000 \\
\hline & Public sector employee & $17.61 \%$ & $22.55 \%$ & 0.000 & $14.70 \%$ & $18.74 \%$ & 0.000 \\
\hline & Self-employed & $16.67 \%$ & $16.56 \%$ & 0.846 & $6.70 \%$ & $6.18 \%$ & 0.223 \\
\hline & Civil Servant & $15.50 \%$ & $19.19 \%$ & 0.000 & $11.77 \%$ & $13.90 \%$ & 0.000 \\
\hline \multirow{2}{*}{ Unemployment } & Unemployment duration (months) & 73.03 & 62.33 & 0.000 & 87.4 & 72.9 & 0.000 \\
\hline & Unemployment benefit level ( $€ /$ month) & $€ 834$ & $€ 705$ & 0.000 & $€ 660$ & $€ 597$ & 0.000 \\
\hline \multirow{3}{*}{ Actual working time } & $1 \%-30 \%$ & $3.26 \%$ & $2.44 \%$ & 0.000 & $11.40 \%$ & $9.00 \%$ & 0.000 \\
\hline & $31 \%-80 \%$ & $14.53 \%$ & $12.27 \%$ & 0.000 & $43.59 \%$ & $43.01 \%$ & 0.224 \\
\hline & $81 \%-100 \%$ & $82.21 \%$ & $85.29 \%$ & 0.000 & $45.02 \%$ & $47.99 \%$ & 0.000 \\
\hline \multirow{15}{*}{ Sector (Nace Rev. 1.) } & Nace 1-19 & $4.27 \%$ & $4.45 \%$ & 0.178 & - & - & - \\
\hline & Nace $20-29$ & $12.68 \%$ & $15.75 \%$ & 0.000 & - & - & - \\
\hline & Nace $30-39$ & $3.96 \%$ & $5.87 \%$ & 0.000 & - & - & - \\
\hline & Nace $40-49$ & $9.35 \%$ & $9.12 \%$ & 0.396 & - & - & - \\
\hline & Nace 50-59 & $11.01 \%$ & $9.77 \%$ & 0.000 & $11.33 \%$ & $12.83 \%$ & 0.000 \\
\hline & Nace 60 & $4.54 \%$ & $6.08 \%$ & 0.000 & - & - & - \\
\hline & Nace 61-64 & $4.79 \%$ & $5.53 \%$ & 0.070 & - & - & - \\
\hline & Nace 65-69 & $5.16 \%$ & $5.48 \%$ & 0.097 & - & - & - \\
\hline & Nace $70-74$ & $5.24 \%$ & $5.03 \%$ & 0.231 & $5.86 \%$ & $6.85 \%$ & 0.000 \\
\hline & Nace 75-79 & $18.26 \%$ & $17.85 \%$ & 0.604 & $15.56 \%$ & $17.56 \%$ & 0.080 \\
\hline & Nace $80-84$ & $15.19 \%$ & $9.69 \%$ & 0.000 & $34.74 \%$ & $26.54 \%$ & 0.000 \\
\hline & Nace 85-89 & $2.80 \%$ & $3.26 \%$ & 0.048 & $14.51 \%$ & $15.37 \%$ & 0.270 \\
\hline & Nace 90-99 & $2.75 \%$ & $2.13 \%$ & 0.006 & $4.11 \%$ & $3.90 \%$ & 0.520 \\
\hline & Nace 1-49 & - & - & - & $7.11 \%$ & $9.66 \%$ & 0.000 \\
\hline & Nace 60-69 & - & - & - & $6.78 \%$ & $7.28 \%$ & 0.290 \\
\hline Career break & Career break & $2.77 \%$ & $2.08 \%$ & 0.000 & $9.16 \%$ & $11.26 \%$ & 0.000 \\
\hline \multirow{3}{*}{ Working time } & Full-time & $92.04 \%$ & $93.82 \%$ & 0.000 & $63.72 \%$ & $54.15 \%$ & 0.000 \\
\hline & Part-time & $7.37 \%$ & $5.60 \%$ & 0.000 & $35.11 \%$ & $44.32 \%$ & 0.000 \\
\hline & Special time & $0.59 \%$ & $0.58 \%$ & 0.810 & $1.17 \%$ & $1.53 \%$ & 0.030 \\
\hline
\end{tabular}




\begin{tabular}{|c|c|c|c|c|c|c|c|}
\hline \multirow{9}{*}{ Firm size } & $<5$ & $5.10 \%$ & $4.31 \%$ & 0.000 & $7.71 \%$ & $7.71 \%$ & 0.990 \\
\hline & $5-9$ & $4.05 \%$ & $3.83 \%$ & 0.100 & $4.09 \%$ & $4.32 \%$ & 0.410 \\
\hline & $10-19$ & $5.34 \%$ & $5.00 \%$ & 0.030 & $4.46 \%$ & $4.43 \%$ & 0.940 \\
\hline & $20-49$ & $9.38 \%$ & $9.06 \%$ & 0.180 & $5.68 \%$ & $6.65 \%$ & 0.010 \\
\hline & $50-99$ & $6.09 \%$ & $6.17 \%$ & 0.700 & $3.83 \%$ & $4.80 \%$ & 0.010 \\
\hline & $100-199$ & $6.65 \%$ & $7.06 \%$ & 0.160 & $4.28 \%$ & $5.14 \%$ & 0.030 \\
\hline & $200-499$ & $9.91 \%$ & $9.98 \%$ & 0.860 & $7.00 \%$ & $8.38 \%$ & 0.020 \\
\hline & $500-999$ & $6.76 \%$ & $7.20 \%$ & 0.220 & $6.18 \%$ & $6.94 \%$ & 0.180 \\
\hline & $1000+$ & $46.74 \%$ & $47.41 \%$ & 0.370 & $56.80 \%$ & $51.64 \%$ & 0.000 \\
\hline \multirow{2}{*}{ Experience (in quarters) } & $28-5.5$ years before & 52.44 & 55.145 & 0.000 & 26.711 & 33.723 & 0.000 \\
\hline & $2.75-1.75$ years before & 1.4027 & 2.0366 & 0.000 & 0.6293 & 1.0622 & 0.000 \\
\hline \multirow{2}{*}{ Never employed } & $28-5.5$ years before & $22.45 \%$ & $17.06 \%$ & 0.000 & $43.10 \%$ & $29.19 \%$ & 0.000 \\
\hline & $2.75-1.75$ years before & $69.06 \%$ & $56.47 \%$ & 0.000 & $86.05 \%$ & $76.57 \%$ & 0.000 \\
\hline \multirow{2}{*}{ Severance payment (times) } & $28-5.5$ years before & 0.4797 & 0.4576 & 0.130 & 0.3578 & 0.3223 & 0.030 \\
\hline & $2.75-1.75$ years before & 0.0058 & 0.0043 & 0.100 & 0.0059 & 0.0044 & 0.300 \\
\hline \multirow{2}{*}{ Share of time blue-collar } & $28-5.5$ years before & $55.80 \%$ & $54.98 \%$ & 0.190 & $49.58 \%$ & $45.72 \%$ & 0.000 \\
\hline & $2.75-1.75$ years before & $45.67 \%$ & $52.08 \%$ & 0.000 & $39.50 \%$ & $37.25 \%$ & 0.020 \\
\hline \multirow{2}{*}{ Working time } & $10.75-5.5$ years before & $60.08 \%$ & $59.87 \%$ & 0.740 & $33.61 \%$ & $36.25 \%$ & 0.000 \\
\hline & $2.75-1.75$ years before & $85.25 \%$ & $87.17 \%$ & 0.000 & $66.29 \%$ & $68.50 \%$ & 0.000 \\
\hline Full-time quarterly earnings & $2.75-1.75$ years before & $€ 9,550$ & $€ 8,929$ & 0.000 & $€ 6,497$ & $€ 6,552$ & 0.380 \\
\hline $\mathrm{N}$ observation & - & 298,337 & 460,240 & - & 150,897 & 293,941 & - \\
\hline $\mathrm{N}$ individuals (clusters) & - & 65,908 & 86,107 & - & 33,432 & 55,403 & - \\
\hline
\end{tabular}

Descriptive statistics for the units in the baseline model (i.e. treated 58-59.5 years old; control 53.25-55.25 years old). The reported means are weighted by the sampling weights defined in Equation (2) in the main text. In this descriptive analysis values of variables are set to missing, and hence ignored in the calculation of the sample means, if the value is not known for this individual (e.g. the wage for people not employed or the unemployment benefit if not unemployed). In the CDiD analysis the values of these variables are set to zero instead. The p-values reported are for the t-tests of equality of means allowing for individual serial correlation (cluster robust SES).

Figure A.1: Parallel path and Trend: outcome variables after IPW weights
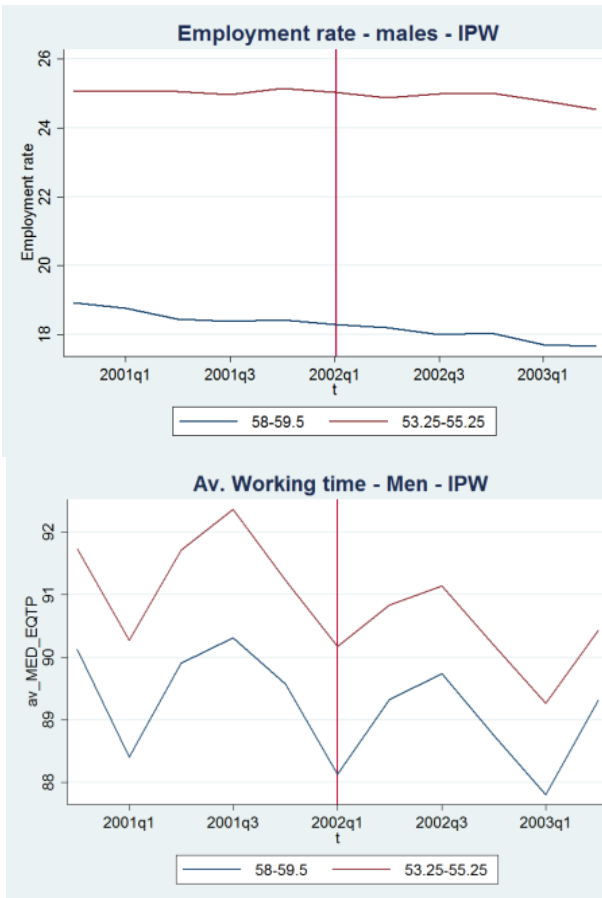

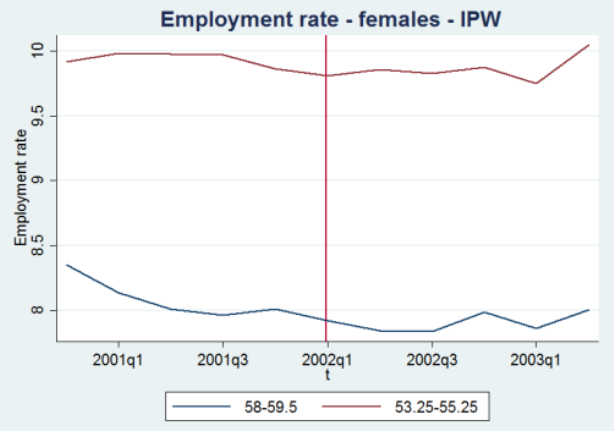

Av. Working time - Women - IPW

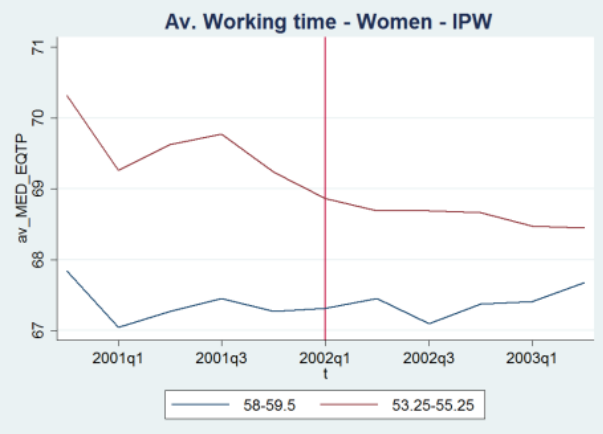



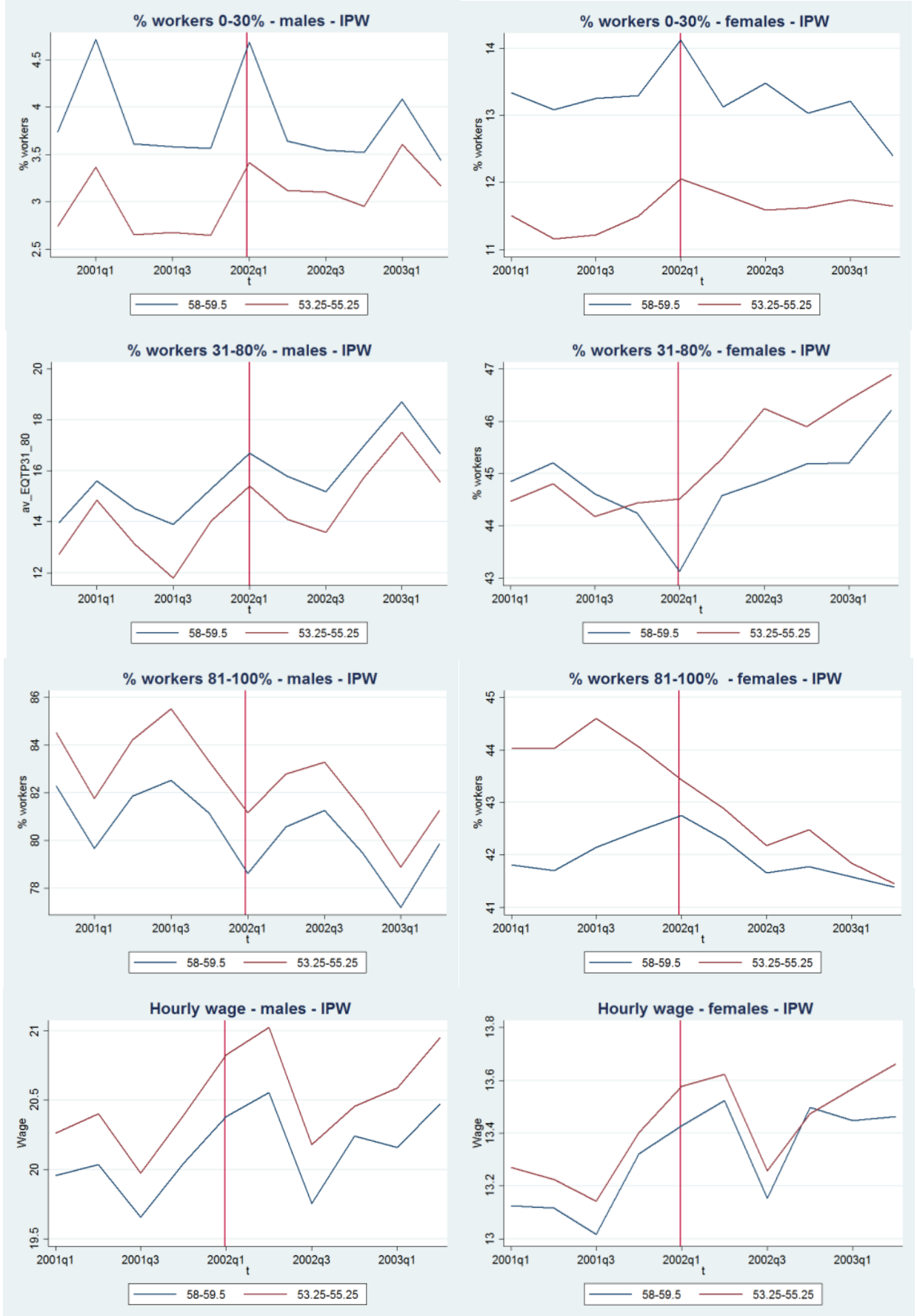
Table A.2: Impact on the Hourly Gross Wage: control group 53.25-55.25 years old

\begin{tabular}{|c|c|c|c|c|c|c|c|c|c|c|}
\hline Men & Overall (1) & Low wage (2) & \begin{tabular}{|l|} 
Manufacturing Sector (3) \\
\end{tabular} & \begin{tabular}{|l|} 
Service sector (4) \\
\end{tabular} & High exit rate (5) & Low exit rate (6) & \begin{tabular}{|l|} 
Large firms (7) \\
\end{tabular} & Small firms (8) & Blue-collar (9) & \begin{tabular}{|l|} 
White-collar (10) \\
\end{tabular} \\
\hline ATT in $€$ & -0.07 & \begin{tabular}{|l|}
0.05 \\
\end{tabular} & \begin{tabular}{|l|}
-0.02 \\
\end{tabular} & 0.19 & 0.03 & \begin{tabular}{|l|}
0.24 \\
\end{tabular} & 0.05 & 0.09 & 0.03 & 0.06 \\
\hline $95 \% \mathrm{Cl}$ & {$[-0.32 ; 0.19]$} & {$[-0.01 ; 0.11]$} & {$[-0.35 ; 0.30]$} & {$[-0.11 ; 0.49]$} & {$[-0.15 ; 0.21]$} & {$[-0.12 ; 0.61]$} & {$[-0.24 ; 0.33]$} & {$[-0.17 ; 0.34]$} & {$[-0.03 ; 0.10]$} & {$[-0.27 ; 0.04]$} \\
\hline Pvalue & 0.604 & 0.089 & 0.891 & 0.209 & 0.752 & 0.192 & 0.747 & 0.513 & 0.348 & 0.717 \\
\hline ATT in \% & $-0.3 \%$ & $0.4 \%$ & $-0.1 \%$ & $1.0 \%$ & $0.2 \%$ & $1.0 \%$ & $0.2 \%$ & $0.5 \%$ & $0.2 \%$ & $0.2 \%$ \\
\hline $\mathrm{N}^{\circ}$ of observations & 389,986 & 240,111 & 203,832 & 181,563 & 230,551 & 134,223 & 208,084 & 181,897 & 195,516 & 166,993 \\
\hline $\mathbf{N}^{\circ}$ of individuals & 92,630 & 57,941 & 48,093 & 44,332 & 55,844 & 33,764 & 50,129 & 44,757 & 46,904 & 40,077 \\
\hline Elasticity & -0.093 & 0.087 & -0.031 & 0.249 & 0.040 & 0.342 & 0.066 & 0.119 & 0.045 & 0.088 \\
\hline Elasticity Upper Cl & 0.270 & 0.166 & 0.412 & 0.666 & 0.273 & 0.863 & 0.470 & 0.421 & 0.148 & 0.571 \\
\hline
\end{tabular}

\begin{tabular}{|c|c|c|c|c|c|c|c|c|c|c|}
\hline Women & Overall (1) & Low wage (2) & Manufacturing Sector (3) & Service sector(4) & High exit rate (5) & Low exit rate (6) & Large firms (7) & Small firms (8) & Blue-collar (9) & White-collar (10) \\
\hline ATT in $€$ & 0.01 & 0.01 & $0.24 *$ & -0.03 & 0.05 & 0.01 & -0.04 & $0.09 *$ & 0.03 & -0.03 \\
\hline $95 \% \mathrm{Cl}$ & {$[-0.07 ; 0.10]$} & {$[-0.05 ; 0.08]$} & {$[-0.03 ; 0.51]$} & {$[-0.12 ; 0.05]$} & {$[-0.07 ; 0.16]$} & {$[-0.12 ; 0.13]$} & {$[-0.18 ; 0.10]$} & {$[-0.01 ; 0.20]$} & {$[-0.05 ; 0.11]$} & {$[-0.14 ; 0.08]$} \\
\hline Pvalue & 0.750 & 0.697 & 0.081 & 0.436 & 0.420 & 0.932 & 0.547 & 0.090 & 0.490 & 0.576 \\
\hline ATT in \% & $0.1 \%$ & $0.1 \%$ & $1.7 \%$ & $-0.3 \%$ & $0.4 \%$ & $0.0 \%$ & $-0.3 \%$ & $0.8 \%$ & $0.3 \%$ & $-0.2 \%$ \\
\hline $\mathbf{N}^{\circ}$ of observations & 223,918 & 104,112 & 36,274 & 184,691 & 102,560 & 102,470 & 107,409 & 116,305 & 65,242 & 139,641 \\
\hline $\mathrm{N}^{\circ}$ of individuals & 53,222 & 26,186 & 8,587 & 43,939 & 25,325 & 24,399 & 25,733 & 28,534 & 16,383 & 32,455 \\
\hline Elasticity & 0.018 & 0.018 & 0.356 & -0.046 & 0.063 & 0.007 & -0.055 & 0.124 & 0.040 & -0.042 \\
\hline Elasticity Upper Cl & 0.137 & 0.140 & 0.755 & 0.135 & 0.271 & 0.137 & 0.131 & 0.274 & 0.142 & 0.139 \\
\hline
\end{tabular}

WDiD on parallel path: impact on the hourly gross wage. Control group is 53.25-55.25 years old; treated group 58-59.5 years old. Effects on specific subpopulation (defined in time q) by column: (1) Overall treated group, (2) Workers earning less than the treatment group median wage, (3) Workers in secondary sector, (4) Workers in tertiary sector, (5) Workers in sectoral industrial committees with an exit rate from employment above the median (=18\%), (6) Workers in sectoral industrial committees with an exit rate below the median, (7) Workers in firms with at least 200 employees, (8) Workers in firms with less than 200 employees, (9) Blue-collar workers, (10) White-collar workers. $N^{\circ}$ of observations is the sum of the number of individuals observed in each quarter of the analysis. Standard errors are obtained by a stratified bootstrap

(clustering by individual) with 200 repetitions and $95 \%$ confidence intervals (CI) by assuming normality. ${ }^{* * *}$ : significant at $1 \%, * *$ : significant at $5 \%, *^{*}$ : significant at $10 \%$. 
Table A.3: Impact on the Employment Rate (Extensive Margin): control group 53.25-57 years old

\begin{tabular}{|c|c|c|c|c|c|c|c|c|c|c|c|}
\hline Men & $\begin{array}{l}\text { Overall } \\
\text { (1) }\end{array}$ & $\begin{array}{c}\text { Already } \\
\text { Working (2) }\end{array}$ & $\begin{array}{l}\text { Low wage } \\
\text { (3) }\end{array}$ & $\begin{array}{c}\text { Manufacturing } \\
\text { Sector (4) }\end{array}$ & $\begin{array}{l}\text { Service } \\
\text { sector (5) }\end{array}$ & $\begin{array}{l}\text { High exit rate } \\
\text { Committee (6) }\end{array}$ & $\begin{array}{l}\text { Low exit rate } \\
\text { Committee (7) }\end{array}$ & $\begin{array}{l}\text { Large firms } \\
\text { (8) }\end{array}$ & $\begin{array}{l}\text { Small firms } \\
\text { (9) }\end{array}$ & $\begin{array}{l}\text { Blue-collar } \\
\text { (10) }\end{array}$ & $\begin{array}{c}\text { White-collar } \\
\text { (11) }\end{array}$ \\
\hline ATT in $p p$ & $0.7^{* * *}$ & $2.2^{* * *}$ & 1.2 & $3.5^{* * *}$ & 0.5 & $3.2^{* * *}$ & 0.1 & $4.0^{* * *}$ & -0.5 & 0.6 & $1.9^{*}$ \\
\hline $95 \% \mathrm{Cl}$ & {$[0.2 ; 1.2]$} & {$[0.8 ; 3.6]$} & {$[-0.9,3.3]$} & {$[1.4,5.7]$} & {$[-1.5 ; 2.5]$} & {$[1.3,5.0]$} & {$[-2.4,2.5]$} & {$[1.7 ; 6.4]$} & {$[-2.4 ; 1.5]$} & {$[-1.5 ; 2.8]$} & {$[-0.2 ; 4.1]$} \\
\hline Pvalue & 0.004 & 0.002 & 0.278 & 0.001 & 0.617 & 0.001 & 0.967 & 0.001 & 0.642 & 0.565 & 0.073 \\
\hline ATT \% & $4.0 \%$ & $3.5 \%$ & $2.1 \%$ & $6.8 \%$ & $0.7 \%$ & $5.9 \%$ & $0.1 \%$ & $6.8 \%$ & $-0.7 \%$ & $1.2 \%$ & $2.7 \%$ \\
\hline $\mathbf{N}^{\circ}$ of observations & $1,135,596$ & 811,981 & 475,377 & 459,360 & 343,377 & 526,758 & 285,060 & 446,649 & 363,630 & 453,725 & 358,090 \\
\hline $\mathbf{N}^{\circ}$ of individuals & 152,280 & 123,519 & 77,403 & 69,197 & 55,170 & 82,887 & 46,873 & 68,858 & 59,850 & 70,570 & 53,934 \\
\hline Subsidy/Labor cost & $3.7 \%$ & $3.6 \%$ & $5.0 \%$ & $3.4 \%$ & $3.8 \%$ & $4.3 \%$ & $3.0 \%$ & $2.9 \%$ & $4.4 \%$ & $4.4 \%$ & $4.4 \%$ \\
\hline Elasticity & 1.084 & 0.965 & 0.41 & 2.006 & 0.179 & 1.364 & 0.023 & 2.336 & -0.155 & 0.233 & 0.73 \\
\hline Semi-Elasticity in $p p$ & 0.187 & 0.611 & 0.231 & 1.051 & 0.133 & 0.736 & 0.017 & 1.387 & -0.106 & 0.146 & 0.448 \\
\hline
\end{tabular}

\begin{tabular}{|c|c|c|c|c|c|c|c|c|c|c|c|}
\hline Women & $\begin{array}{l}\text { Overall } \\
\text { (1) }\end{array}$ & $\begin{array}{c}\text { Already } \\
\text { Working (2) }\end{array}$ & $\begin{array}{l}\text { Low wage } \\
\text { (3) }\end{array}$ & $\begin{array}{l}\text { Manufacturing } \\
\text { Sector (4) }\end{array}$ & $\begin{array}{c}\text { Service } \\
\text { sector (5) }\end{array}$ & $\begin{array}{l}\text { High exit rate } \\
\text { Committee (6) }\end{array}$ & $\begin{array}{l}\text { Low exit rate } \\
\text { Committee (7) }\end{array}$ & $\begin{array}{l}\text { Large firms } \\
\text { (8) }\end{array}$ & $\begin{array}{l}\text { Small firms } \\
\text { (9) }\end{array}$ & $\begin{array}{c}\text { Blue-collar } \\
\text { (10) }\end{array}$ & $\begin{array}{c}\text { White-collar } \\
\text { (11) }\end{array}$ \\
\hline ATT in $p p$ & $0.5^{* * *}$ & 1.7 & 1.9 & 2.7 & 1.3 & $4.9 * * *$ & -0.4 & 1.9 & 1.3 & 2.2 & 1.6 \\
\hline $95 \% \mathrm{Cl}$ & {$[0.1 . ; 0.9]$} & {$[-0.6 ; 3.9]$} & {$[-1.3,5.1]$} & {$[-3.3,8.7]$} & {$[-1.1,3.8]$} & {$[1.5 ; 8.2]$} & {$[-3.7,2.9]$} & {$[-1.3 ; 5.1]$} & {$[-1.1,3.8]$} & {$[-1.9 ; 6.4]$} & {$[-1.1 ; 4.4]$} \\
\hline Pvalue & 0.002 & 0.151 & 0.254 & 0.377 & 0.288 & 0.004 & 0.813 & 0.253 & 0.422 & 0.290 & 0.247 \\
\hline ATT \% & $6.7 \%$ & $2.5 \%$ & $2.8 \%$ & $5.0 \%$ & $1.8 \%$ & $8.5 \%$ & $-0.5 \%$ & $3.0 \%$ & $1.7 \%$ & $3.7 \%$ & $2.3 \%$ \\
\hline $\mathbf{N}^{\circ}$ of observations & 660,465 & 422,126 & 208,550 & 76,784 & 339,573 & 218,856 & 203,239 & 208,655 & 213,404 & 143,008 & 278,991 \\
\hline $\mathrm{N}^{\circ}$ of individuals & 89,062 & 65,118 & 36,509 & 11,724 & 52,760 & 35,853 & 32,108 & 32,184 & 35,525 & 24,229 & 41,488 \\
\hline Subsidy/Labor cost & $5.5 \%$ & $5.4 \%$ & $7.6 \%$ & $4.5 \%$ & $5.5 \%$ & $5.7 \%$ & $5.2 \%$ & $4.9 \%$ & $6.0 \%$ & $6.0 \%$ & $6.0 \%$ \\
\hline Elasticity & 1.220 & 0.459 & 0.376 & 1.137 & 0.341 & 1.478 & -0.100 & 0.614 & 0.291 & 0.530 & 0.381 \\
\hline Semi-Elasticity in $p p$ & 0.090 & 0.311 & 0.247 & 0.606 & 0.242 & 0.849 & -0.077 & 0.378 & 0.214 & 0.369 & 0.268 \\
\hline
\end{tabular}

WDiD on parallel growths: impact on the employment rate. Control group is 53.25-57 years old; treated group 58-59.5 years old. Effects on specific subpopulation (defined in q-7) by column: (1) Overall treated group, (2) Workers earning less than the treatment group median wage, (3) Workers in secondary sector, (4) Workers in tertiary sector, (5) Workers in sectoral industrial committees with an exit rate from employment above the median ( $18 \%)$ ), (6) Workers in sectoral industrial committees with an exit rate below the median, (7) Workers in firms with at least 200 employees, (8) Workers in firms with less than 200 employees, (9) above the median $(=18 \%),(6)$ Workers in sectoral industrial committees with an exit rate below the median, (7) Workers in firms with at least 200 employees, (8) Workers in firms with less than 200 employees, (9)
Blue-collar workers, (10) White-collar workers. Point estimates of the ATT are expressed in percentage points (pp), in proportional (\%) changes in the employment rate and in terms of (semi-)elasticity, i.e. the proportional ( $p p)$ effect on the employment rate of a proportional reduction in the labour costs. $N^{\circ}$ of observations is the sum of the number of individuals observed in each quarter of the analysis. Standard errors are obtained by a stratified bootstrap (clustering by individual) with 200 repetitions and $95 \%$ confidence intervals (CI) by assuming normality. ${ }^{* * *}$ : significant at $1 \%$, **: significant at $5 \%,{ }^{*}$ : significant at $10 \%$. 
Table A.4: Impact on the intensive margin: control group 53.25-57 years old

\begin{tabular}{|c|c|c|c|c|c|c|c|c|c|c|c|}
\hline & & Overall (1) & Low Wage (2) & Manufacturing Sector (3) & Service Sector (4) & High Exit Rate (5) & Low Exit Rate (6) & Large Firms (7) & Small Firms (8) & Blue-collar (9) & White-collar (10) \\
\hline \multirow{17}{*}{ Men } & 0\%-30\%: ATT in $p p$ & $-0.5^{* * * *}$ & $-0.5^{* *}$ & $-0.3^{*}$ & $-0.5^{* * * *}$ & $-0.6 * * *$ & -0.1 & $-0.2^{*}$ & $-0.5^{* *}$ & $-0.5^{* *}$ & -0.0 \\
\hline & $95 \% \mathrm{Cl}$ & {$[-0.8 ;-0.2]$} & {$[-0.9 ;-0.1]$} & {$[-0.7 ; 0.01]$} & {$[-0.9 ;-0.2]$} & {$[-1 ;-0.2]$} & {$[-0.4 ; 0.2]$} & {$[-0.5 ; 0.02]$} & {$[-0.9 ;-0.1]$} & {$[-1.1 ;-0.01]$} & {$[-0.2 ; 0.2]$} \\
\hline & Pvalue & 0.001 & 0.012 & 0.054 & 0.006 & 0.002 & 0.499 & 0.074 & 0.026 & 0.046 & 0.742 \\
\hline & ATT in \% & $-11.6 \%$ & $-8.8 \%$ & $-12.2 \%$ & $-12.0 \%$ & $-12.9 \%$ & $-5.5 \%$ & $-13.0 \%$ & $-8.0 \%$ & $-8.4 \%$ & $-3.1 \%$ \\
\hline & $31 \%-80 \%:$ ATT in $p p$ & -0.1 & -0.2 & -0.5 & 0.0 & -0.4 & -0.3 & 0.1 & -0.3 & -0.4 & -0.3 \\
\hline & $95 \% \mathrm{Cl}$ & {$[-0.6 ; 0.5]$} & {$[-1.1 ; 0.7]$} & {$[-1.3 ; 0.4]$} & {$[-0.9 ; 0.8]$} & {$[-1.3 ; 0.4]$} & {$[-1.1 ; 0.6]$} & {$[-0.8 ; 0.9]$} & {$[-1.1 ; 0.5]$} & {$[-1.4 ; 0.6]$} & {$[-1 ; 0.4]$} \\
\hline & Pvalue & 0.816 & 0.673 & 0.262 & 0.972 & 0.295 & 0.543 & 0.892 & 0.590 & 0.426 & 0.392 \\
\hline & ATT in \% & $-0.4 \%$ & $-0.9 \%$ & $-3.1 \%$ & $-0.1 \%$ & $-2.4 \%$ & $-1.8 \%$ & $0.4 \%$ & $-1.6 \%$ & $-1.8 \%$ & $-2.3 \%$ \\
\hline & $>80 \%$ : ATT in $p p$ & $0.5^{*}$ & 0.7 & $0.8^{*}$ & 0.6 & $1.1^{* *}$ & 0.3 & 0.2 & $0.8^{* *}$ & $0.9^{*}$ & 0.3 \\
\hline & $95 \% \mathrm{Cl}$ & {$[-1.1 ; 0.3]$} & {$[-0.2 ; 1.6]$} & {$[-0.1 ; 1.7]$} & {$[-0.2 ; 1.4]$} & {$[0.2 ; 1.9]$} & {$[-0.5 ; 1.2]$} & {$[-0.7 ; 1.1]$} & {$[0.02 ; 1.6]$} & {$[-0.1 ; 1.9]$} & {$[-0.4 ; 1]$} \\
\hline & Pvalue & 0.080 & 0.129 & 0.067 & 0.163 & 0.014 & 0.427 & 0.704 & 0.044 & 0.065 & 0.354 \\
\hline & ATT in \% & $0.7 \%$ & $1.0 \%$ & $1.0 \%$ & $-0.7 \%$ & $1.4 \%$ & $0.4 \%$ & $0.2 \%$ & $1.1 \%$ & $1.3 \%$ & $0.4 \%$ \\
\hline & ATT total hours \% & $0.4 \% * *$ & $0.4 \% *$ & $0.5 \% *$ & $0.4 \%$ & $0.8 \%^{* * *}$ & $0.2 \%$ & $0.1 \%$ & $0.6 \% * *$ & $0.6 \% *$ & $0.1 \%$ \\
\hline & $95 \% \mathrm{Cl}$ & {$[0.0 ; 0.7]$} & {$[0.0 ; 0.7]$} & {$[0.0 ; 0.9]$} & {$[-0.1 ; 0.8]$} & {$[0.2 ; 1.1]$} & {$[-0.3 ; 0.6]$} & {$[-0.4 ; 0.5]$} & {$[0.1 ; 0.9]$} & {$[0 ; 1.1]$} & {$[-0.3 ; 0.5]$} \\
\hline & Elasticity & 0.108 & 0.093 & 0.146 & 0.108 & 0.174 & 0.064 & 0.040 & 0.128 & 0.125 & 0.048 \\
\hline & $\mathrm{N}^{\circ}$ of observations & 648,229 & 396,060 & 342,423 & 298,233 & 382,139 & 225,610 & 342,967 & 305,255 & 321,214 & 282,392 \\
\hline & $\mathrm{N}^{\circ}$ of individuals & 107,974 & 68,563 & 57,244 & 51,325 & 66,399 & 39,911 & 59,195 & 53,667 & 55,550 & 46,384 \\
\hline \multirow{17}{*}{ Women } & 0\%-30\%: ATT in $p p$ & $-0.5^{*}$ & -0.5 & 1.0 & $-0.7 * *$ & $-0.8^{*}$ & 0.1 & $-0.6^{*}$ & -0.5 & -0.3 & -0.2 \\
\hline & $95 \% \mathrm{Cl}$ & {$[-1.1 ; 0.1]$} & {$[-1.4 ; 0.5]$} & {$[-0.5 ; 2.4]$} & {$[-1.2 ;-0.1]$} & {$[-1.7 ; 0.1]$} & {$[-0.5 ; 0.6]$} & {$[-1.3 ; 0.1]$} & {$[-1.3 ; 0.3]$} & {$[-1.5 ; 0.9]$} & {$[-0.7 ; 0.3]$} \\
\hline & Pvalue & 0.077 & 0.352 & 0.196 & 0.029 & 0.092 & 0.846 & 0.098 & 0.236 & 0.597 & 0.334 \\
\hline & ATT in \% & $-3.9 \%$ & $-2.4 \%$ & $11.1 \%$ & $-5.0 \%$ & $-5.1 \%$ & $0.7 \%$ & $-9.3 \%$ & $-2.7 \%$ & $-1.3 \%$ & $-5.1 \%$ \\
\hline & 31\%-80\%: ATT in $p p$ & $-1.1^{* *}$ & $-1.6^{* *}$ & -0.3 & $-1.2^{* *}$ & -0.6 & $-1.8^{* * *}$ & $-2.1 * * *$ & -0.6 & -0.8 & $-1.4^{* * *}$ \\
\hline & $95 \% \mathrm{Cl}$ & {$[-2.0 ;-0.2]$} & {$[-2.9 ;-0.2]$} & {$[-2.9 ; 2.1]$} & {$[-2.2 ;-0.2]$} & {$[-2 ; 0.8]$} & {$[-2.9 ;-0.6]$} & {$[-3.5 ;-0.7]$} & {$[-1.8 ; 0.7]$} & {$[-2.5 ; 0.9]$} & {$[-2.4 ;-0.3]$} \\
\hline & Pvalue & 0.015 & 0.024 & 0.822 & 0.019 & 0.412 & 0.003 & 0.004 & 0.365 & 0.344 & 0.008 \\
\hline & ATT in \% & $-2.4 \%$ & $-2.9 \%$ & $-0.9 \%$ & $-2.5 \%$ & $-1.2 \%$ & $-3.9 \%$ & $-4.0 \%$ & $-1.4 \%$ & $-1.6 \%$ & $-3.0 \%$ \\
\hline & $>80 \%$ : ATT in $p p$ & $1.6^{* * *}$ & $2.0^{* * *}$ & -0.6 & $1.9 * * *$ & $1.4^{* * *}$ & $1.7^{* * *}$ & $2.7^{* * *}$ & $1.1^{*}$ & 1.2 & $1.6^{* * *}$ \\
\hline & $95 \% \mathrm{Cl}$ & {$[0.7,2.3]$} & {$[1.0 ; 3.1]$} & {$[-3.1 ; 1.9]$} & {$[1 ; 2.8]$} & {$[0.2 ; 2.5]$} & {$[0.6 ; 2.8]$} & {$[1.5 ; 4]$} & {$[-0.03 ; 2.2]$} & {$[-0.2 ; 2.5]$} & {$[0.7 ; 2.5]$} \\
\hline & Pvalue & 0.000 & 0.000 & 0.618 & 0.000 & 0.022 & 0.004 & 0.000 & 0.057 & 0.101 & 0.001 \\
\hline & ATT in \% & $4.1 \%$ & $7.3 \%$ & $-1.2 \%$ & $4.8 \%$ & $3.8 \%$ & $3.7 \%$ & $6.668 \%$ & $2.7 \%$ & $4.9 \%$ & $3.2 \%$ \\
\hline & ATT total hours $\%$ & $1.4 \% * * *$ & $2.1 \%^{* * *}$ & $0.0 \%$ & $1.6 \%^{* * *}$ & $1.5 \%^{* * *}$ & $1.1 \%^{* *}$ & $2.0 \% * * *$ & $1.3 \%^{* *}$ & $1.9 \%^{* *}$ & $0.9 \%^{* * *}$ \\
\hline & $95 \% \mathrm{Cl}$ & {$[0.8 ; 1.4]$} & {$[1.0 ; 1.9]$} & {$[-1.8 ; 1.4]$} & {$[0.8 ; 1.6]$} & {$[0.5 ; 1.6]$} & {$[0.3 ; 1.4]$} & {$[1.1 ; 2]$} & {$[0.2 ; 1.4]$} & {$[0.3 ; 1.9]$} & {$[0.3 ; 1.2]$} \\
\hline & Elasticity & 0.264 & 0.278 & 0.007 & 0.293 & 0.259 & 0.213 & 0.401 & 0.201 & 0.250 & 0.193 \\
\hline & $\mathrm{N}^{\circ}$ of observations & 334,197 & 154,033 & 54,378 & 275,663 & 153,797 & 152,568 & 162,395 & 171,502 & 96,797 & 209,222 \\
\hline & $\mathbf{N}^{\circ}$ of individuals & 58,205 & 29,278 & 9,573 & 48,010 & 28,183 & 26,566 & 28,363 & 31,601 & 18,326 & 34,955 \\
\hline
\end{tabular}


Table A.5: Impact on the Hourly Gross Wage: control group 53.25-57 years old

\begin{tabular}{|c|c|c|c|c|c|c|c|c|c|c|}
\hline Men & Overall (1) & Low wage (2) & Manufacturing Sector (3) & Service sector (4) & High exit rate (5) & Low exit rate (6) & Large firms (7) & Small firms (8) & Blue-collar (9) & White-collar (10) \\
\hline ATT in $€$ & 0.06 & 0.01 & -0.33 & $0.21 *$ & 0.01 & $0.34^{* * *}$ & 0.08 & 0.14 & 0.01 & $0.20^{*}$ \\
\hline $95 \% \mathrm{Cl}$ & {$[-0.08 ; 0.19]$} & {$[-0.05 ; 0.07]$} & {$[-0.73 ; 0.07]$} & {$[-0.01 ; 0.44]$} & {$[-0.13 ; 0.15]$} & {$[0.11 ; 0.57]$} & {$[-0.15 ; 0.31]$} & {$[-0.03 ; 0.32]$} & {$[-0.05 ; 0.06]$} & {$[-0.01 ; 0.41]$} \\
\hline Pvalue & 0.421 & 0.735 & 0.107 & 0.058 & 0.931 & 0.004 & 0.503 & 0.105 & 0.843 & 0.060 \\
\hline ATT in \% & $0.3 \%$ & $0.1 \%$ & $-1.5 \%$ & $1.1 \%$ & $0.0 \%$ & $1.4 \%$ & $0.3 \%$ & $0.9 \%$ & $0.0 \%$ & $0.0 \%$ \\
\hline $\mathrm{N}^{\circ}$ of observations & 581,180 & 356,134 & 305,982 & 268,396 & 344,243 & 200,070 & 306,613 & 274,566 & 288,870 & 251,735 \\
\hline $\mathrm{N}^{\circ}$ of individuals & 103,296 & 65,585 & 54,682 & 48,973 & 63,708 & 37,718 & 56,338 & 50,790 & 53,332 & 44,099 \\
\hline Elasticity & 0.075 & 0.017 & -0.441 & 0.281 & 0.008 & 0.440 & 0.110 & 0.201 & 0.009 & 0.287 \\
\hline Elasticity Upper Cl & 0.270 & 0.166 & 0.095 & 0.530 & 0.135 & 0.783 & 0.441 & 0.421 & 0.088 & 0.571 \\
\hline
\end{tabular}

\begin{tabular}{|c|c|c|c|c|c|c|c|c|c|c|}
\hline Women & Overall (1) & Low wage (2) & \begin{tabular}{|l|} 
Manufacturing Sector (3) \\
\end{tabular} & Service sector (4) & High exit rate (5) & Low exit rate (6) & \begin{tabular}{|l|} 
Large firms (7) \\
\end{tabular} & Small firms (8) & Blue-collar (9) & White-collar (10) \\
\hline ATT in $€$ & -0.01 & 0.00 & $0.21^{*}$ & -0.05 & 0.03 & -0.02 & -0.04 & 0.06 & 0.02 & -0.04 \\
\hline $95 \% \mathrm{Cl}$ & {$[-0.08 ; 0.07]$} & {$[-0.06 ; 0.07]$} & {$[-0.03 ; 0.46]$} & {$[-0.14 ; 0.04]$} & {$[-0.07 ; 0.13]$} & {$[-0.12 ; 0.08]$} & {$[-0.16 ; 0.08]$} & {$[-0.04 ; 0.16]$} & {$[-0.06 ; 0.09]$} & {$[-0.14 ; 0.06]$} \\
\hline Pvalue & 0.884 & 0.934 & 0.086 & 0.257 & 0.570 & 0.703 & 0.499 & 0.262 & 0.631 & 0.448 \\
\hline ATT in \% & $0.0 \%$ & $0.0 \%$ & $1.5 \%$ & $-0.4 \%$ & $0.2 \%$ & $-0.1 \%$ & $-0.3 \%$ & $0.5 \%$ & $0.2 \%$ & $0.4 \%$ \\
\hline $\mathbf{N}^{\circ}$ of observations & 333,652 & 153,826 & 54,126 & 275,255 & 153,603 & 152,304 & 162,029 & 171,323 & 96,684 & 208,898 \\
\hline $\mathrm{N}^{\circ}$ of individuals & 58,138 & 29,249 & 9,536 & 47,950 & 28,166 & 26,548 & 28,319 & 31,570 & 18,312 & 34,934 \\
\hline Elasticity & -0.008 & 0.004 & 0.318 & -0.070 & 0.040 & -0.027 & -0.053 & 0.079 & 0.026 & -0.053 \\
\hline Elasticity Upper $\mathrm{Cl}$ & 0.137 & 0.140 & 0.755 & 0.054 & 0.136 & 0.134 & 0.131 & 0.274 & 0.142 & 0.139 \\
\hline
\end{tabular}

WDiD on parallel path: impact on the hourly gross wage. Control group is 53.25-57 years old; treated group 58-59.5 years old. Effects on specific subpopulation (defined in time q) by column: (1) Overall treated group,

(2) Workers earning less than the treatment group median wage, (3) Workers in secondary sector. (4) Workers in tertiary sector, (5) Workers in sectoral industrial committees with an exit rate from employment above the median $(=18 \%)$, (6) Workers in sectoral industrial committees with an exit rate below the median, (7) Workers in firms with at least 200 employees, (8) Workers in firms with less than 200 employees, (9) Blue-collar workers, (10) White-collar workers. $N^{\circ}$ of observations is the sum of the number of individuals observed in each quarter of the analysis. Standard errors are obtained by a stratified bootstrap (clustering by individual) with 200 repetitions and $95 \%$ confidence intervals (CI) by assuming normality. ${ }^{* * *}$ : significant at $1 \%$, **: significant at $5 \%$, *: significant at $10 \%$. 


\section{References}

Abadie, A., 2005. Semiparametric Difference-in-Differences Estimators. Review of Economic Studies 72, 119.

Ammermüller, A., Boockmann, B., Maier, M., Zwick, T., 2006. Eingliederungszuschüsse und Entgeltsicherung für Ältere: Analysen auf Basis natürlicher Experimente. Vierteljahrshefte zur Wirtschaftsforschung / Quarterly Journal of Economic Research 75, 49-66.

Athey, S., Imbens, G., 2006. Identification and Inference in Nonlinear Difference-in-Differences Models. Econometrica 74, 431-497.

Aubert, P., Crépon, B., 2003. La productivité des salariés âgés: une tentative d’estimation. Économie et statistique $368,95-119$.

Aubert, P., Crépon, B., 2006. Are older workers less productive? Firm-level evidence on age-productivity and age-wage profiles. mimeo, INSEE, Paris.

Barrios Cobos, S., Saveyn, B., Pycroft, J., 2013. The Marginal Cost of Public Funds in the Eu: The Case of Labour Versus Green Taxes. Taxation papers 35, Publications Office of the European Union.

Bell, B., Blundell, R., van Reenen, J., 1999. Getting the Unemployed Back to Work: The Role of Targeted Wage Subsidies. International Tax and Public Finance 6, 339-360.

Bennmarker, H., Mellander, E., Öckert, B., 2009. Do Regional Payroll Tax Reductions Boost Employment? Labour Economics 16, 480-489.

Blau, D., 1994. Labor Force Dynamics of Older Men. Econometrica 62, 117-56.

Blau, D., Riphahn, R., 1999. Labor force transitions of older married couples in Germany. Labour Economics 6, 229-252.

Blundell, R., Costa Dias, M., 2009. Alternative Approaches to Evaluation in Empirical Microeconomics. Journal of Human Resources 44, 565-640.

Blundell, R., Costa Dias, M., Meghir, C., Reenen, J., 2004. Evaluating the Employment Impact of a Mandatory Job Search Program. Journal of the European Economic Association 2, 569-606.

Bohm, P., Lind, H., 1993. Policy Evaluation Quality: A Quasi-Experimental Study of Regional Employment Subsidies in Sweden. Regional Science and Urban Economics 23, 51-65.

Boockmann, B., Zwick, T., Ammermüller, A., Maier, M., 2012. Do Hiring Subsidies Reduce Unemployment Among Older Workers? Evidence from Natural Experiments. Journal of the European Economic Association 10, 735-764.

Brussig, M., Bernhard, S., Jaenichen, U., Zwick, T., 2006. Zielstellung, Förderstrukturen Und Effekte Der „entgeltsicherung “-Erfahrungen Mit Einem Kombilohn Für Ältere Arbeitnehmerinnen Und Arbeitnehmer. Zeitschrift für ArbeitsmarktForschung 39, 491-504.

Burtless, G., 1986. Social Security, Unanticipated Benefit Increases, and the Timing of Retirement. Review of Economic Studies 53, 781-805.

Busso, M., DiNardo, J., McCrary, J., 2014. New Evidence on the Finite Sample Properties of Propensity Score Reweighting and Matching Estimators. The Review of Economics and Statistics 96, 885-897.

Cameron, A.C., Trivedi, P.K., 2005. Microeconometrics: methods and applications. Cambridge University Press.

Cardoso, A.R., Guimarães, P., Varejão, J., 2011. Are Older Workers Worthy of Their Pay? An Empirical Investigation of Age-Productivity and Age-Wage Nexuses. De Economist 159, 95-111.

Cataldi, A., Kampelmann, S., Rycx, F., 2012. Does it pay to be productive? The case of age groups. International Journal of Manpower 33, 264-283.

Chabé-Ferret, S., 2012. Matching vs Differencing when Estimating Treatment Effects with Panel Data: the Example of the Effect of Job Training Programs on Earnings. TSE Working Paper No. 12-356, Toulouse School of Economics, Toulouse.

Claes, T., 2012. La Prépension Conventionnelle (1974-2012). Courrier hebdomadaire du CRISP 2154, 5-94.

Cohen, D., Elchardus, M., 2003. Attitude et attentes en rapport avec la fin de la carrière professionnelle. TOR Groep, Vrije Universiteit Brussel, Brussels. 
Crépon, B., Desplatz, R., 2003. The Effets of Payroll Tax Subsidies for Low Wage Workers on Firms Level Decisions . Working Paper Centre de Recherche en Economie et Statistique No. 2003-06, INSEE, Paris.

Crump, R., Hotz, V.J., Imbens, G., Mitnik, O., 2009. Dealing with Limited Overlap in Estimation of Average Treatment Effects. Biometrika 96, 187-199.

Dejemeppe, M., Smith, C., Van der Linden, B., 2015. Did the Intergenerational Solidarity Pact increase the employment rate of the elderly in Belgium? A macro-econometric evaluation . mimeo, IRES, Université catholique de Louvain, Louvain-la-Neuve.

Eissa, N., Hoynes, H.W., 2004. Taxes and the labor market participation of married couples: the Earned Income Tax Credit. Journal of Public Economics 88, 1931-1958.

Eissa, N., Liebman, J., 1996. Labor Supply Response to the Earned Income Tax Credit. The Quarterly Journal of Economics 111, 605-37.

European Commission, 2010. Europe 2020. a Strategy for Smart, Sustainable and Inclusive Growth. Communication from the Commission. COM (2010) 2020 final, 3 March 2010.

Eurostat, 2015. Employment rates by sex, age and nationality: Ifsa_ergan.

French, E., 2005. The Effects of Health, Wealth, and Wages on Labour Supply and Retirement Behaviour. Review of Economic Studies 72, 395-427.

Friedberg, L., 2000. The Labor Supply Effects of the Social Security Earnings Test. The Review of Economics and Statistics 82, 48-63.

Frölich, M., 2007. Propensity Score Matching Without Conditional Independence Assumption-with an Application to the Gender Wage Gap in the United Kingdom. The Econometrics Journal 10, 359407.

Frölich, M., Huber, M., Wiesenfarth, M., 2015. The Finite Sample Performance of Semi- and Nonparametric Estimators for Treatment Effects and Policy Evaluation . IZA Discussion Papers No. 8756, IZA, Bonn

Goos, M., Konings, J., 2007. The Impact of Payroll Tax Reductions on Employment and Wages: A Natural Experiment Using Firm Level Data . LICOS Discussion Paper No. 178/2007.

Gruber, J., 1997. The Incidence of Payroll Taxation: Evidence from Chile. Journal of Labor Economics 15, S72-101.

Gruber, J., Wise, D.A., 2007. Social Security Programs and Retirement around the World: Fiscal Implications of Reform. University of Chicago Press.

Hamermesh, D.S., 1996. Labor demand. Princeton University Press.

Hanoch, G., Honig, M., 1983. Retirement, Wages, and Labor Supply of the Elderly. Journal of Labor Economics 1, 131-51.

Heckman, J., 1974. Shadow Prices, Market Wages, and Labor Supply. Econometrica 42, 679-94.

Heckman, J., Ichimura, H., Todd, P., 1997. Matching as an Econometric Evaluation Estimator: Evidence from Evaluating a Job Training Programme. Review of Economic Studies 64, 605-54.

Hellerstein, J.K., Neumark, D., 2007. Production function and wage equation estimation with heterogeneous labor: Evidence from a new matched employer-employee data set, in: Hard-toMeasure Goods and Services: Essays in Honor of Zvi Griliches. University of Chicago Press, pp. 3171.

Hellerstein, J., Neumark, D., Troske, K., 1999. Wages, Productivity, and Worker Characteristics: Evidence from Plant-Level Production Functions and Wage Equations. Journal of Labor Economics 17, 40946.

Hersoug, T., 1984. Union Wage Responses to Tax Changes. Oxford Economic Papers 36, 37-51.

Hirano, K., Imbens, G.W., Ridder, G., 2003. Efficient Estimation of Average Treatment Effects Using the Estimated Propensity Score. Econometrica 71, 1161-1189.

Horvitz, D.G., Thompson, D.J., 1952. A Generalization of Sampling Without Replacement from a Finite Universe. Journal of the American Statistical Association 47, 663-685.

Huber, M., Lechner, M., Wunsch, C., 2013. The Performance of Estimators Based on the Propensity Score. Journal of Econometrics 175, 1-21.

Huttunen, K., Pirttilä, J., Uusitalo, R., 2013. The Employment Effects of Low-Wage Subsidies. Journal of Public Economics 97, 49-60. 
Ilmakunnas, P., Maliranta, M., 2005. Technology, Labour Characteristics and Wage-productivity Gaps. Oxford Bulletin of Economics and Statistics 67, 623-645.

Imbens, G., Wooldridge, J., 2009. Recent Developments in the Econometrics of Program Evaluation. Journal of Economic Literature 47, 5-86.

Kaldor, N., 1936. Wage Subsidies as a Remedy for Unemployment. Journal of Political Economy 44.

Katz, L., 1996. Wage Subsidies for the Disadvantaged . NBER Working Paper No. 5679.

Keane, M., 2012. Income Taxation in a Life Cycle Model with Human Capital . Economics Series Working Paper, University of Oxford, Oxford No. 2012-W08.

Keane, M., Rogerson, R., 2012. Micro and Macro Labor Supply Elasticities: A Reassessment of Conventional Wisdom. Journal of Economic Literature 50, 464-76.

Kleven, H.J., Kreiner, C., 2006. The Marginal Cost of Public Funds: Hours of Work Versus Labor Force Participation. Journal of Public Economics 90, 1955-1973.

Kramarz, F., Philippon, T., 2001. The Impact of Differential Payroll Tax Subsidies on Minimum Wage Employment. Journal of Public Economics 82, 115-146.

Krueger, A.B., Pischke, J.-S., 1992. The Effect of Social Security on Labor Supply: A Cohort Analysis of the Notch Generation. Journal of Labor Economics 10, 412-37.

Lazear, E., 1979. Why Is Ihere Mandatory Retirement? Journal of Political Economy 87, 1261-84.

Lechner, M., Wunsch, C., 2009. Are Training Programs More Effective When Unemployment Is High? Journal of Labor Economics 27, 653-692.

Lichter, A., Peichl, A., Siegloch, S., 2014. The Own-Wage Elasticity of Labor Demand: A Meta-Regression Analysis . IZA Discussion Paper No. 7958, IZA, Bonn.

Liebman, J.B., Luttmer, E.F.P., Seif, D.G., 2009. Labor supply responses to marginal Social Security benefits: Evidence from discontinuities. Journal of Public Economics 93, 1208-1223.

Lockwood, B., Manning, A., 1993. Wage Setting and the Tax System Theory and Evidence for the United Kingdom. Journal of Public Economics 52, 1-29.

Manski, C., Lerman, S.R., 1977. The Estimation of Choice Probabilities from Choice Based Samples. Econometrica 45, 1977-88.

Marshall, A., 1920. Principals of Economics. MacMillan.

Meyer, B., 1995. Natural and Quasi-experiments in Economics. Journal of Business \& Economic Statistics 13, 151-61.

Meyer, B.D., Rosenbaum, D.T., 2001. Welfare, the Earned Income Tax Credit, and the Labor Supply of Single Mothers. Quarterly Journal of Economics 116, 1063-1114.

Mitchell, O.S., Fields, G.S., 1984. The Economics of Retirement Behavior. Journal of Labor Economics 2, 84105.

OECD, 2003. Ageing and Employment Policies/Vieillissement Et Politiques de L'emploi: Belgium. OECD Publishing, Paris.

OECD, 2007. Society at a Glance 2006. OECD Publishing, Paris.

Pissarides, C., 1985. Taxes, Subsidies, and Equilibrium Unemployment. Review of Economic Studies 52, 121-33.

Pissarides, C., 1998. The Impact of Employment Tax Cuts on Unemployment and Wages; the Role of Unemployment Benefits and Tax Structure. European Economic Review 42, 155-183.

Staubli, S., Zweimüller, J., 2013. Does raising the early retirement age increase employment of older workers? Journal of Public Economics 108, 17-32.

Vandenberghe, V., Waltenberg, F., Rigo, M., 2013. Ageing and Employability. Evidence from Belgian FirmLevel Data. Journal of Productivity Analysis 40, 111-136.

Van Ours, J., Stoeldraijer, L., 2011. Age, Wage and Productivity in Dutch Manufacturing. De Economist 159, 113-137.

Wolfers, J., 2006. Did Unilateral Divorce Laws Raise Divorce Rates? A Reconciliation and New Results. American Economic Review 96, 1802-1820.

Wooldridge, J.M., 2010. Econometric Analysis of Cross Section and Panel Data, 2nd ed. MIT press.

Zabalza, A., Pissarides, C., Barton, M., 1980. Social Security and the Choice Between Full-Time Work, PartTime Work and Retirement. Journal of Public Economics 14, 245-276. 